\title{
Low-carbon economic dispatch for electricity and natural gas systems considering carbon capture systems and power-to-gas
}

\author{
Liangce $\mathrm{He}^{\mathrm{a}}$, Zhigang $\mathrm{Lu}^{\mathrm{a},}{ }^{,}$, Jiangfeng Zhang ${ }^{\mathrm{b}}$, Lijun Geng ${ }^{\mathrm{a}}$, Hao Zhao ${ }^{\mathrm{c}}$, Xueping $\mathrm{Li}^{\mathrm{a}}$ \\ ${ }^{a}$ Key Lab of Power Electronics for Energy Conservation and Motor Drive of Hebei Province, Yanshan University, Qinhuangdao, \\ Hebei, 066004, China \\ ${ }^{b}$ School of Electrical and Data Engineering, University of Technology Sydney, Ultimo, NSW 2007, Australia \\ ${ }^{c}$ China Energy Engineering Group Tianjin Electric Power Design Institute Co., Ltd. , Tianjin 300400, China
}

\begin{abstract}
To mitigate the global warming threat, $\mathrm{CO}_{2}$ emission reduction is an irreversible trend for the sustainable development of power systems. Among various low-carbon technologies, gas-fired power plants and power-to-gas facilities play an important role to reduce emissions, and they increase also the interdependency between electricity and natural gas systems. Considering also the increasing penetration of wind power generation, this paper proposes a low-carbon economic dispatch model under both constraints of the electricity and natural gas systems. To reduce $\mathrm{CO}_{2}$ emission and improve the wind power utilization, mathematical formulations of the post-combustion carbon capture system and power-to-gas facility are presented in the proposed model. Additionally, a flexible operation mode of post-combustion carbon capture system and power-to-gas facility is further analyzed. The objective function of the presented model is to minimize the total cost, which consists of the operation cost, the $\mathrm{CO}_{2}$ processing cost and the penalty cost of wind power curtailment. Then the optimization model is converted into a mixed integer linear programming problem for efficient computation purpose. Numerical case studies are carried out to validate the effectiveness of the proposed model and the flexible operation mode.
\end{abstract}

Keywords: Electricity and natural gas systems, Low-carbon economic dispatch, Flexible operation mode, Post-combustion carbon capture system, Power-to-gas

\section{NOMENCLATURE}

\section{Indices and Sets :}

$c, d, i, k, p, w$
$l, s, \omega$
$m, n$
$t$
$S(m)$

Indices of carbon capture units, electrical loads, generating units, buses, PtG facilities and wind farms

Indices of natural gas loads, gas storage facilities and gas wells

Indices of gas network nodes

Index of hours

Constants :

$$
a_{i}, b_{i}, c_{i} \quad \text { Cost coefficients of unit } i\left(\mathrm{MBtu}, \mathrm{MBtu} / \mathrm{MWh}, \mathrm{MBtu} / \mathrm{MW}^{2} \mathrm{~h}\right)
$$

\footnotetext{
*Corresponding author at: Power Electronics for Energy Conservation and Motor Drive Department, Yanshan University, Qinhuangdao, Hebei 066004 China.

E-mail address: zhglu@ysu.edu.cn (Zhigang Lu).
} 




Characteristics constant of gas pipeline $m n$ (kcf/Psig)

Power transfer distribution factor of transmission line $i j$ of node $k$

Numbers of carbon capture units, $\mathrm{CO}_{2}$ storage facilities, fossil fuel-fired units, gas-fired units

Numbers of buses, electrical loads and hours

Numbers of gas wells, natural gas storage facilities, PtG facilities and wind farms

Min/max pressure of natural gas node $m$ (Psig)

Forecasted values of electrical load $d(\mathrm{MW})$, wind generation of wind farm $w(\mathrm{MW})$ and gas load $l$ (kcf)

Min/Max power flow of transmission line $i j(\mathrm{MW})$

Min/Max power input of PtG facility $p(\mathrm{MW})$

Min/Max power output of PtG facility $p$ (MW)

Min/Max production of gas well $\omega(\mathrm{kcf} / \mathrm{h})$

Maximum injection rate of natural gas $/ \mathrm{CO}_{2} / \mathrm{H}_{2}$ storage facility $s(\mathrm{kcf} / \mathrm{h})$

Maximum withdrawal rate of natural gas $/ \mathrm{CO}_{2} / \mathrm{H}_{2}$ storage facility $s(\mathrm{kcf} / \mathrm{h})$

Ramp up/down rate of unit $i$ (MW)

Start up/Shut down fuel of generating unit $i$ (MBtu)

Up/Down system spinning reverse (MW)

Minimum on/off time of unit $i(\mathrm{~h})$

$\mathrm{CO}_{2}$ capturing rate/energy consumption for dealing with per unit $\mathrm{CO}_{2}$ of carbon capture unit $c(\mathrm{MWh} / \mathrm{kcf})$

$\mathrm{CO}_{2}$ emission intensity of unit $i(\mathrm{kcf} / \mathrm{MWh})$

Node incidence matrix at row $k$ of non-carbon capture unit $a$, carbon capture unit $c$, wind farm $w$, PtG facility $p$ and electrical load $d$

Power to $\mathrm{H}_{2}$ efficiency of PtG facility $p$

Reaction coefficients of $\mathrm{H}_{2}$ to $\mathrm{CO}_{2} / \mathrm{CH}_{4}$

Heat release factor of the Sabatier reaction $(\mathrm{MWh} / \mathrm{kcf})$

Compressing factor of compressor $c$

Fuel price of coal-fired unit $i$ (\$/MBtu), production price of gas well $\omega$ $(\$ / \mathrm{kcf})$, storage price of natural gas storage facility $s(\$ / \mathrm{kcf})$ and penalty 


$$
\rho^{\mathrm{ct}}, \rho^{\mathrm{ts}}, \rho^{\mathrm{cc}}
$$

\section{Variables :}

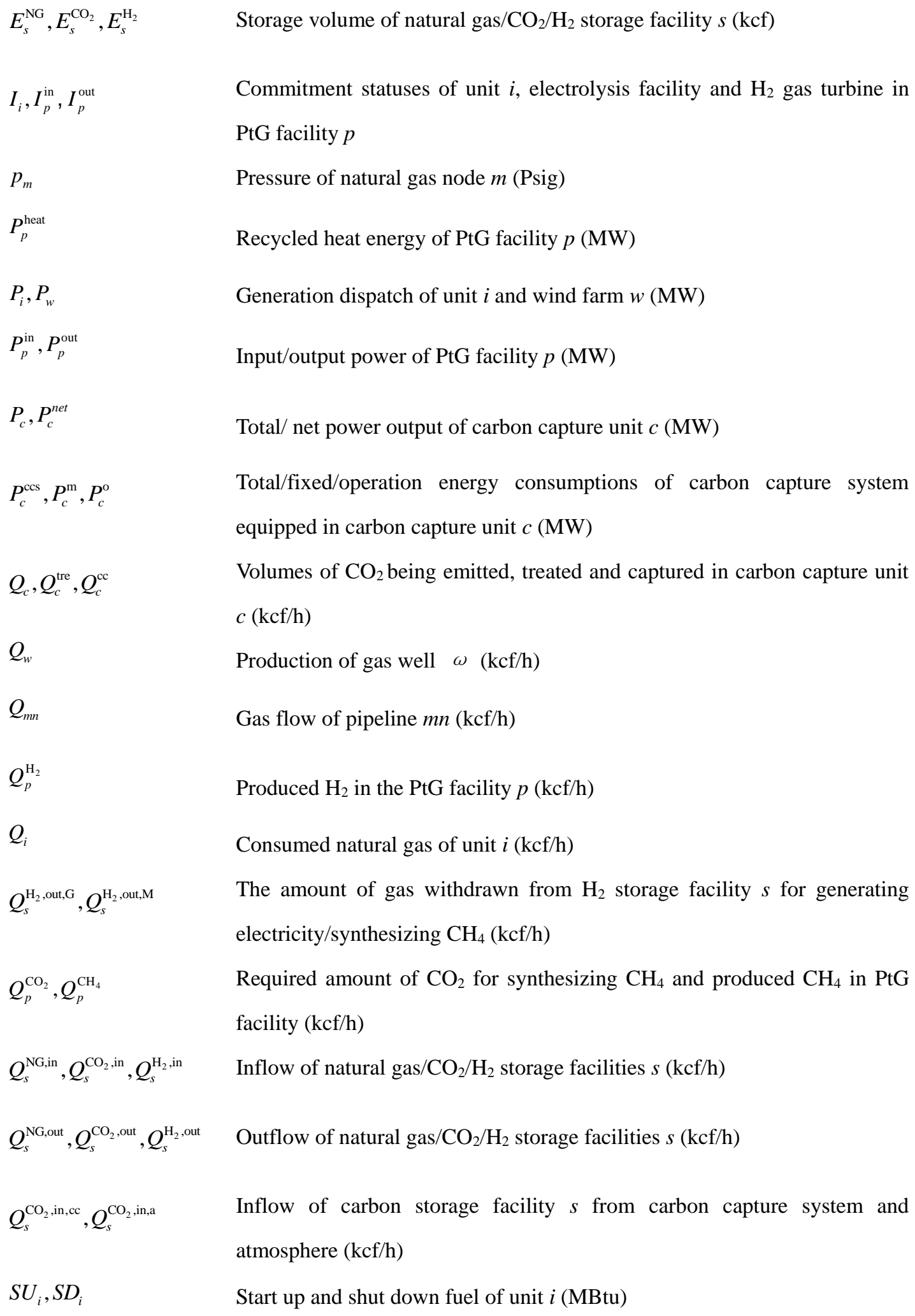

$p_{m} \quad$ Pressure of natural gas node $m$ (Psig)

$Q_{s}^{\mathrm{NG}, \text { out }}, Q_{s}^{\mathrm{CO} 2, \text { out }}, Q_{s}^{\mathrm{H}_{2}, \text { out }} \quad$ Outflow of natural gas $/ \mathrm{CO}_{2} / \mathrm{H}_{2}$ storage facilities $s(\mathrm{kcf} / \mathrm{h})$

Recycled heat energy of PtG facility $p$ (MW)

Generation dispatch of unit $i$ and wind farm $w$ (MW)

Input/output power of PtG facility $p$ (MW)

Total/ net power output of carbon capture unit $c$ (MW)

Total/fixed/operation energy consumptions of carbon capture system equipped in carbon capture unit $c$ (MW)

Volumes of $\mathrm{CO}_{2}$ being emitted, treated and captured in carbon capture unit $c(\mathrm{kcf} / \mathrm{h})$

Production of gas well $\omega(\mathrm{kcf} / \mathrm{h})$

Gas flow of pipeline $m n(\mathrm{kcf} / \mathrm{h})$

Produced $\mathrm{H}_{2}$ in the PtG facility $p(\mathrm{kcf} / \mathrm{h})$

Consumed natural gas of unit $i(\mathrm{kcf} / \mathrm{h})$

The amount of gas withdrawn from $\mathrm{H}_{2}$ storage facility $s$ for generating electricity/synthesizing $\mathrm{CH}_{4}(\mathrm{kcf} / \mathrm{h})$

Required amount of $\mathrm{CO}_{2}$ for synthesizing $\mathrm{CH}_{4}$ and produced $\mathrm{CH}_{4}$ in $\mathrm{PtG}$ facility $(\mathrm{kcf} / \mathrm{h})$

Inflow of natural gas $/ \mathrm{CO}_{2} / \mathrm{H}_{2}$ storage facilities $s(\mathrm{kcf} / \mathrm{h})$

Inflow of carbon storage facility $s$ from carbon capture system and atmosphere $(\mathrm{kcf} / \mathrm{h})$

Start up and shut down fuel of unit $i$ (MBtu)

price of wind power curtailment for wind farm $w$ ( $\$ / \mathrm{MWh}$ )

Carbon tax price (\$/ton), $\mathrm{CO}_{2}$ transmission \& storage price $\left(\$ /\right.$ ton), and $\mathrm{CO}_{2}$ capture price from atmosphere $(\$ /$ ton $)$ 


\section{Introduction}

Global warming caused by greenhouse gas emission is a crucial issue in the world, and limiting global warming to $2.0^{\circ} \mathrm{C}$ above pre-industrial levels and aspiring to $1.5^{\circ} \mathrm{C}$ are the targets pursued in future sustainable development [1]. As a primary greenhouse gas, $\mathrm{CO}_{2}$ accounts for more than $70 \%$ of greenhouse gas emission [2]. Therefore, $\mathrm{CO}_{2}$ emission reduction has become an important problem in the study of power dispatch at fossil fuel-fired power plants, which emit significant portions of $\mathrm{CO}_{2}$ into the atmosphere.

Nowadays, different measures can be taken to decrease the $\mathrm{CO}_{2}$ emission in power plants. Within fossil fuel power plants, more natural gas-fired power plants should be encouraged to built due to their advantages of higher generation efficiency, faster ramp speed and lower $\mathrm{CO}_{2}$ emission intensity against conventional coal-fired power plants [3]. Meanwhile, the carbon capture and storage (CCS) technology can contribute to form the carbon capture power plants (CCPPs) for reducing the $\mathrm{CO}_{2}$ emission [4], since the replacement of existing coal-fired power plants takes quite a long time period. Moreover, renewable energy sources, such as wind energy, can be widely developed thanks to their increasing maturity of generation technology and nearly zero $\mathrm{CO}_{2}$ emission. However, with the increasing penetration of wind power, more and more generation cannot be completely utilized and will have to be curtailed. Power-to-gas $(\mathrm{PtG})$ is a promising technology to address this issue, which can convert excess power of wind power into hydrogen $\left(\mathrm{H}_{2}\right)$ by water electrolysis and further into methane $\left(\mathrm{CH}_{4}\right)$ via Sabatier reaction [5].

Different from obtaining coal on site in many coal-fired power plants, the fuel of gas-fired power plants is mainly provided by natural gas pipelines. A large amount of synthesizing $\mathrm{CH}_{4}$ from $\mathrm{PtG}$ facilities can be injected into the natural gas pipelines directly to serve other gas users [6]. Thus, a bidirectional energy conversion between the power system and natural gas system is achieved by gas-fired power plants and PtG facilities [7]. With the significant growth of the installed capacity of natural gas-fired power plants and PtG facilities, the interdependence of electricity and natural gas systems becomes more significant [8]. Therefore, the operation conditions of natural gas system need to be considered in the low-carbon economic dispatch of power systems.

Due to the above reasons, the unit commitment (UC) problem of power systems has been studied in [9-13] by considering the gas supply contracts and network security constraints of natural gas system. The hourly UC and dispatch of power system in [9] are determined by considering the constraints of electricity and natural gas networks, and Newton-Raphson method is adopted to solve the nonlinear natural gas flow equations. Uncertainty factors including load forecast errors, random outages of generating units and transmission lines are considered in [10] to the security-constrained unit commitment (SCUC) model, and hourly electricity demand response model is added in [11] to maximize the expected social welfare of power systems. The impacts of natural gas price fluctuation and wind power forecast uncertainty on the SCUC are discussed in [12]. A two stage stochastic mixed-integer linear program (MILP) model is proposed in [13] under natural gas pipeline congestion and gas price variability. However, the electrical power system is optimized singly in these studies, which may result in compromised operation of the natural gas system.

Therefore, it is necessary to study power dispatch by optimizing both the electric system and the natural gas system. In [14], a MILP security-constrained optimal power and gas flow model is 
formulated, and contingency analysis of natural gas system is introduced using linear sensitivity factors. A short-term dispatch of electricity and natural gas systems is developed in [15] considering the dynamic process involving gas travel velocity and line pack of natural gas system. Reference [16] proposes a robust dispatch model to address the wind power uncertainty issue considering the power system contingency and natural gas pipeline contingency at the same time. A comprehensive model for an electricity and natural gas coupled network is proposed in [17] which considers also wind power uncertainty. After that, an interval optimization model of electricity and natural gas systems is further studied in an incentive-based demand response program [18]. In [19], wind power and combined cooling, heating and power (CCHP) are studied in an optimal dispatch model of the integrated energy systems. Coupled by gas-fired units and distributed district heating and cooling systems, a coordinated dispatch strategy is proposed in [20] to optimize the conflicting benefits of the electricity network and natural gas network.

Most of the above research in [9-20] mainly considers the linkage of electricity and natural gas systems by gas-fired units, whereas the PtG technology with large-scale wind power integration is not discussed. Connected by gas-fired units and PtG technology, a bi-level economic dispatch model is proposed in [21] to optimize the total production cost of electricity and natural gas systems. In [22], the PtG technology is introduced to absorb the excess wind power otherwise being curtailed, and the corresponding optimization model is calculated by the alternating direction method of multipliers (ADMM) algorithm. In addition, the produced $\mathrm{H}_{2}$ can also be utilized to generate electricity by gas turbines or fuel cells except for its normal usage to synthesize $\mathrm{CH}_{4}$ [23-24]. The $\mathrm{H}_{2}$ buffer and fuel cell are equipped in the PtG facility to maximize the expected profit, and a dual decomposition algorithm is proposed to solve the presented two layer optimization problem in [23]. Aiming at accommodating the surplus wind power in the SCUC problem, an energy hub (EH) is formed in [24] by the PtG facility consisting of an electrolysis facility, a $\mathrm{H}_{2}$ storage facility and a gas turbine. Furthermore, it is important to note that the CCPP and PtG facility are not considered simultaneously in the aforementioned studies. CCPP can improve the utilization of wind power and reduce $\mathrm{CO}_{2}$ emission, while extra fuel has to be consumed to maintain the $\mathrm{CO}_{2}$ capture process of the carbon capture system [25]. Since a $\mathrm{CO}_{2}$ source is required for synthesizing $\mathrm{CH}_{4}$ in the $\mathrm{PtG}$ facility, $\mathrm{CO}_{2}$ can be provided by the atmosphere, biogas plants, biomass gasification, industrial process and CCPPs [26]. For example, in [27] $\mathrm{CO}_{2}$ is provided by the flue gas of a coal-fired power plant, and $\mathrm{H}_{2}$ and $\mathrm{CO}_{2}$ are synthesized to $\mathrm{CH}_{4}$ through the Sabatier reaction, which is an exothermal reaction and the released energy can be further utilized for the carbon capture systems. Based on these advantages, it will bring great economic benefits if the carbon capture system and PtG facility are jointly operated.

In consideration of the above premises, this paper aims at presenting a low-carbon economic dispatch model for the coupled electricity and natural gas systems, which considers the post-combustion carbon capture system and PtG facility under high wind power penetration level. In addition to the operation cost and the penalty cost of wind power curtailment, $\mathrm{CO}_{2}$ processing cost is also considered in the objective function, where this $\mathrm{CO}_{2}$ processing cost includes the carbon tax cost of fossil fuel units, $\mathrm{CO}_{2}$ transmission and storage cost of CCPPs and the $\mathrm{CO}_{2}$ capturing cost from the atmosphere. Moreover, a flexible operation mode, i.e. combining the post-combustion carbon capture system with PtG facility under two different $\mathrm{H}_{2}$ applications, is formulated in the proposed model. Briefly, the major contributions of this paper are summarized as follows.

1) A low-carbon economic dispatch model under the constraints of both the electricity and natural gas systems is proposed, where the objects of study include the gas-fired power plants, coal-fired 
power plants, wind farms, CCPPs and PtG facilities. The target is to minimize the total cost, which includes the operation cost, $\mathrm{CO}_{2}$ processing cost and penalty cost of wind power curtailment.

2) To reduce the $\mathrm{CO}_{2}$ emission and increase the wind power utilization, the post-combustion carbon capture system and PtG facility are both considered in the proposed model. In addition, a flexible operation mode of post-combustion carbon capture system and PtG facility is illustrated and analyzed.

3) In the case studies, sensitivity of carbon tax price and wind power penetration level is presented, and the cost-benefit analysis of different cases is further discussed.

The rest of this paper is organized as follows. Section 2 describes the mathematical models and a flexible operation mode of the post-combustion carbon capture system and PtG facility. Section 3 presents the low carbon economic dispatch model of electricity and natural gas systems. Several case studies are discussed in Section 4. Finally, Section 5 draws the main conclusions.

\section{System description and mathematical modeling}

\subsection{Carbon capture system}

In order to reduce $\mathrm{CO}_{2}$ emission, fossil fuel-fired power plants can be equipped with different carbon capture technologies. At present, three main technologies for $\mathrm{CO}_{2}$ capture are available, i.e., pre-combustion, oxy fuel combustion and post-combustion technologies [25]. In this paper, only the post-combustion carbon capture system is considered and its structure is shown in Fig. 1 [28]. The flue gas from a fossil fuel power plant can be controlled to either emit directly into the air by venting facility or flow into the solvent absorber. Then the solvent containing $\mathrm{CO}_{2}$ in absorber is transported into the stripper for $\mathrm{CO}_{2}$ regeneration. Finally, the separated $\mathrm{CO}_{2}$ from the stripper will be compressed by compressors and transported by pipelines, ships or trucks to store in suitable places, mainly including depleted oil and gas reservoirs, unsinkable coal beds, saline aquifers and basalts.

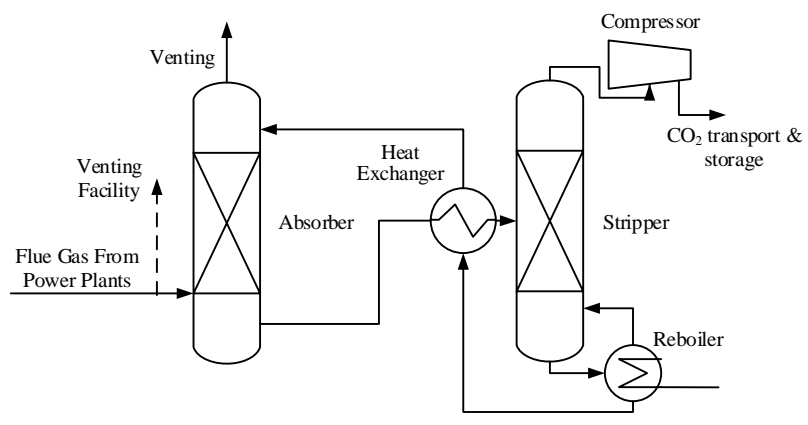

Fig. 1. Structure of the post-combustion carbon capture system [28]

Due to the energy consumption of carbon capture systems, the net power output of the CCPP to supply electrical loads is equal to the difference of the total power output and carbon capture power consumption, which can be expressed as:

$$
P_{c}^{\mathrm{net}}=P_{c}-P_{c}^{\mathrm{ccs}}
$$

The total $\mathrm{CO}_{2}$ volume in the flue gas is determined by the total power output and $\mathrm{CO}_{2}$ emission intensity of the corresponding CCPP:

$$
Q_{c}=\mu_{c} P_{c}
$$

In addition, the power consumption of a carbon capture system consists of two parts, i.e., the fixed power consumption ** and the operation power consumption **.

$$
P_{c}^{\mathrm{ccs}}=P_{c}^{\mathrm{m}}+P_{c}^{\mathrm{o}}
$$

The fixed power consumption is irrelevant to the operational status of carbon capture system and can be regarded as a constant. The operation power consumption refers to the total energy consumption in the whole process of $\mathrm{CO}_{2}$ capture, which is proportional to the amount of treated $\mathrm{CO}_{2}$ in the carbon capture system (4), and the amount of treated $\mathrm{CO}_{2}$ must not exceed the total $\mathrm{CO}_{2}$ emission in the flue 
gas (5).

$$
\begin{gathered}
P_{c}^{\mathrm{o}}=\gamma_{c} Q_{c}^{\text {tre }} \\
0 \leq Q_{c}^{\text {tre }} \leq Q_{c}
\end{gathered}
$$

According to the existing technical specifications, the maximum capture rate of carbon capture systems is about $90 \%$. The captured $\mathrm{CO}_{2}$ of the carbon capture system can be shown as

$$
Q_{c}^{\mathrm{cc}}=\beta_{c} Q_{c}^{\mathrm{re}}
$$

Please note that all the gas volumes in this paper are considered under normal condition with the temperature of $0{ }^{\circ} \mathrm{C}$ and pressure of $1 \mathrm{~atm}$.

\subsection{Power-to-gas facility}

To maintain certain levels of system reliability, excess wind power cannot be supplied directly to the electrical load. The PtG technology can address this issue successfully, and a widely adopted PtG facility is depicted in Fig. 2. Electricity energy and $\mathrm{H}_{2} \mathrm{O}$ are supplied to the electrolysis facility for water electrolysis reaction, and three different technologies can be considered, i.e. alkaline water electrolysis (AWE), acidic proton exchange membrane electrolysis (PEME) and solid oxide electrolysis (SOE) [29]. After that, the produced $\mathrm{H}_{2}$ is directly fed into the methanation facility for synthesizing $\mathrm{CH}_{4}$ by the Sabatier reaction. In this paper, the required $\mathrm{CO}_{2}$ is captured from either the atmosphere or fossil-fired power plants, and the recycled heat can be further utilized for carbon capture systems, which will be considered in the flexible operation mode.

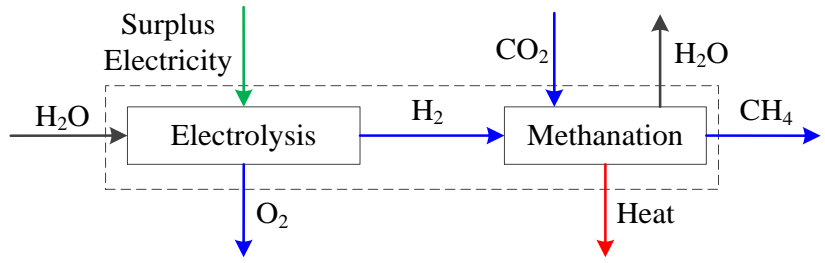

Fig. 2. PtG facility

In the electrolysis facility, the obtained $\mathrm{H}_{2}$ can be modeled as

$$
Q_{p}^{\mathrm{H}_{2}}=\frac{P_{p}^{\mathrm{in}} \eta_{p}^{\mathrm{H}_{2}}}{\mathrm{HHV}_{\mathrm{H}_{2}}}
$$

In the methanation facility, the required $\mathrm{CO}_{2}$ and produced $\mathrm{CH}_{4}$ can be calculated by Sabatier reaction factors:

$$
\begin{aligned}
Q_{p}^{\mathrm{CO}_{2}} & =Q_{p}^{\mathrm{H}_{2}} \cdot \phi_{\mathrm{H}_{2}-\mathrm{CO}_{2}} \\
Q_{p}^{\mathrm{CH}_{4}} & =Q_{p}^{\mathrm{H}_{2}} \cdot \phi_{\mathrm{H}_{2}-\mathrm{CH}_{4}}
\end{aligned}
$$

The input power of the PtG facility is often restricted within certain boundaries. For instance, the AWE technology for the electrolysis facility can be applied for large size plants [30], and should be operated between $20 \%$ to $100 \%$ of the designed capacity. Therefore, the following inequalities hold.

$$
I_{p}^{\text {in }} P_{p, \text { min }}^{\text {in }} \leq P_{p}^{\text {in }} \leq I_{p}^{\text {in }} P_{p, \text { max }}^{\text {in }}
$$

\subsection{Flexible operation mode of carbon capture system and $P t G$ facility}

Based on the operation characteristics of post combustion carbon capture systems and PtG facilities, the overall operation cost will be reduced from two aspects if the carbon capture system and PtG facility can be operated together. One aspect is that the captured $\mathrm{CO}_{2}$ of carbon capture systems can be supplied to the PtG facility for the Sabatier reaction. Compared to other additional $\mathrm{CO}_{2}$ sources, the captured $\mathrm{CO}_{2}$ of carbon capture system can be considered as free. Another aspect is to recycle the heat release of Sabatier reaction for the $\mathrm{CO}_{2}$ regeneration process in the stripper of carbon capture system, so part of the carbon capturing energy consumption will be saved to increase the net power output of CCPP. However, the operation feasibility and flexibility may be limited due to the following reasons. 
First, $\mathrm{CH}_{4}$ is synthesized only during the wind power curtailing period, whereas the $\mathrm{CO}_{2}$ capture process may occur in the whole dispatch cycle. In the worst scenario, all the required $\mathrm{CO}_{2}$ for synthesizing $\mathrm{CH}_{4}$ has to be captured from the atmosphere. Second, $\mathrm{H}_{2}$ and $\mathrm{CH}_{4}$ are produced in a continuous process as shown by the $\mathrm{PtG}$ facility in Fig. 2. In reality, $\mathrm{H}_{2}$ can be utilized for other processes, such as generating electricity by gas turbines and fuel cells, which sometimes may be more economical than converted directly into $\mathrm{CH}_{4}$.

Therefore, in order to improve the operation feasibility and flexibility, a flexible operation mode of the carbon capture system and PtG facility is proposed in Fig. 3. To ensure that the required $\mathrm{CO}_{2}$ for the Sabatier reaction is mainly provided by carbon capture systems, a $\mathrm{CO}_{2}$ storage facility is added between the outlet of carbon capture system and methanation facility. In addition, a $\mathrm{H}_{2}$ storage facility is installed between the electrolysis facility and methanation facility. $\mathrm{H}_{2}$ from storage facility can be withdrawn to generate electricity by gas turbines or synthesize $\mathrm{CH}_{4}$.

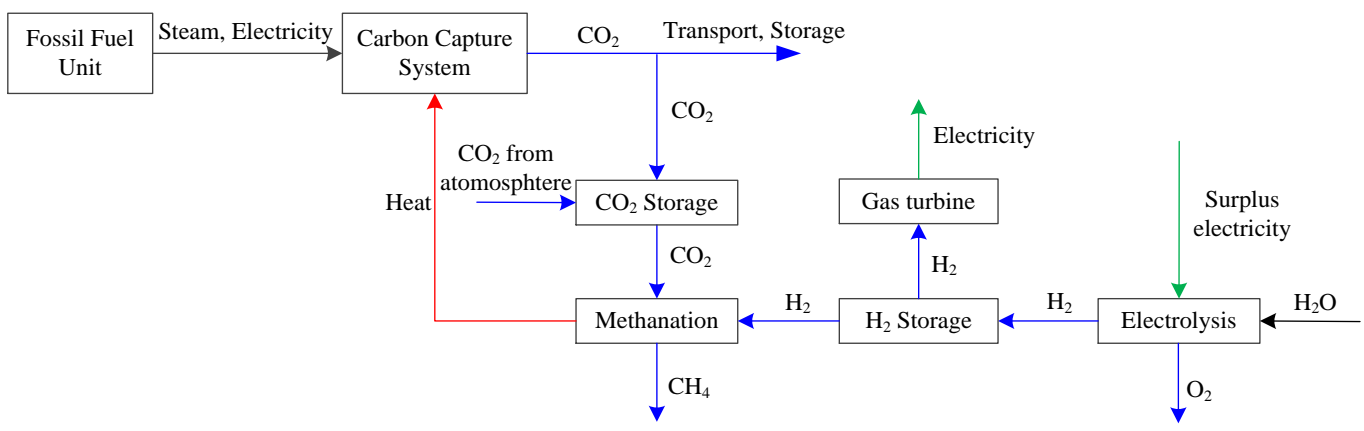

Fig. 3. Flexible operation mode of carbon capture system and PtG facility

\subsection{1. $\mathrm{H}_{2}$ storage facility}

In the proposed flexible operation mode, all the produced $\mathrm{H}_{2}$ by water electrolysis is injected into the $\mathrm{H}_{2}$ storage facility.

$$
Q_{s}^{\mathrm{H}_{2}, \text { in }}=Q_{p}^{\mathrm{H}_{2}}
$$

The storage capacity balance, minimum and maximum injection and withdrawal rates of $\mathrm{H}_{2}$ can be expressed as

$$
\begin{gathered}
E_{s t}^{\mathrm{H}_{2}}=E_{s, t-1}^{\mathrm{H}_{2}}+\left(Q_{s t}^{\mathrm{H}_{2}, \text { in }}-Q_{s t}^{\mathrm{H}_{2}, \text { out }}\right) \Delta t \\
E_{s, \text { min }}^{\mathrm{H}_{2}} \leq E_{s t}^{\mathrm{H}_{2}} \leq E_{s, \text { max }}^{\mathrm{H}_{2}} \\
0 \leq Q_{s t}^{\mathrm{H}_{2}, \text { out }} \leq Q_{s, \text { max }}^{\mathrm{H}_{2}, \text { out }} \\
0 \leq Q_{s t}^{\mathrm{H}_{2} \text {,in }} \leq Q_{s, \text { max }}^{\mathrm{H}_{2}, \text { in }}
\end{gathered}
$$

To ensure sustainable gas supply, the storage volume at the end of dispatch cycle is set to be the same as the beginning period.

$$
E_{s, 0}^{\mathrm{H}_{2}}=E_{s, N_{T}}^{\mathrm{H}_{2}}
$$

Moreover, the outflow from the $\mathrm{H}_{2}$ storage facility includes two different parts for synthesizing $\mathrm{CH}_{4}$ and generating electricity, and can be modeled as:

$$
\left\{\begin{array}{l}
Q_{s}^{\mathrm{H}_{2}, \text { out }}=Q_{s}^{\mathrm{H}_{2}, \text { out }, \mathrm{M}}+Q_{s}^{\mathrm{H}_{2}, \text { out }, \mathrm{G}} \\
Q_{s}^{\mathrm{H}_{2}, \text { out }, \mathrm{M}} \geq 0 \\
Q_{s}^{\mathrm{H}_{2}, \text { out }, \mathrm{G}} \geq 0
\end{array}\right.
$$

\subsubsection{Gas turbine}

For the gas turbine, the relationship between the consumed volume of $\mathrm{H}_{2}$ and electricity power 
generation can be modeled as a quadratic function in (18).

$$
G\left(P_{p}^{\text {out }}\right)=a_{p}+b_{p} P_{p}^{\text {out }}+c_{p}\left(P_{p}^{\text {out }}\right)^{2}
$$

Meanwhile, $\mathrm{H}_{2}$ is also consumed in the start up and shut down processes, so the total $\mathrm{H}_{2}$ consumption of gas turbine can be expressed as:

$$
Q_{s}^{\mathrm{H}_{2}, \text { out }, \mathrm{G}}=\left(G\left(P_{p}^{\text {out }}\right)+S U_{p}+S D_{p}\right) / \mathrm{HHV}_{\mathrm{H}_{2}}
$$

where $\mathrm{HHV}_{\mathrm{H}_{2}}$ is the higher heating value of $\mathrm{H}_{2}$.

Furthermore, the power outputs of gas turbines in the $\mathrm{PtG}$ facilities are limited by their lower and upper bounds (20), and the PtG gas turbine only generates electricity to supply the electric load at time periods when wind power is not curtailed (21).

$$
\begin{gathered}
I_{p}^{\text {out }} P_{p, \text { min }}^{\text {out }} \leq P_{p}^{\text {out }} \leq I_{p}^{\text {out }} P_{p, \text { max }}^{\text {out }} \\
I_{p}^{\text {in }}+I_{p}^{\text {out }} \leq 1
\end{gathered}
$$

\subsection{3. $\mathrm{CO}_{2}$ storage facility}

Similar to the constraints of $\mathrm{H}_{2}$ storage facility, the $\mathrm{CO}_{2}$ storage capacity balance, minimum and maximum injection and withdraw rates satisfy the following constraints:

$$
\begin{gathered}
E_{s t}^{\mathrm{CO}_{2}}=E_{s, t-1}^{\mathrm{CO}_{2}}+\left(Q_{s t}^{\mathrm{CO}_{2} \text {,in }}-Q_{s t}^{\mathrm{CO}_{2}, \text { out }}\right) \Delta t \\
E_{s, \text { min }}^{\mathrm{CO}_{2}} \leq E_{s t}^{\mathrm{CO}_{2}} \leq E_{s, \text { max }}^{\mathrm{CO}_{2}} \\
0 \leq Q_{s t}^{\mathrm{CO}_{2} \text {,out }} \leq Q_{s, \text { max }}^{\mathrm{CO}_{2} \text {,ut }} \\
0 \leq Q_{s t}^{\mathrm{CO}_{2} \text {,in }} \leq Q_{s, \text { max }}^{\mathrm{CO}_{2} \text {,in }} \\
E_{s, 0}^{\mathrm{CO}_{2}}=E_{s, N_{T}}^{\mathrm{CO}_{2}}
\end{gathered}
$$

The $\mathrm{CO}_{2}$ inflow of the storage facility can be provided by the carbon capture system or the atmosphere:

$$
Q_{s}^{\mathrm{CO}_{2}, \mathrm{in}}=Q_{s}^{\mathrm{CO}_{2}, \mathrm{in}, \mathrm{cc}}+Q_{s}^{\mathrm{CO}_{2}, \text { in,a }}
$$

\subsubsection{Methanation facility}

Based on the reaction factors in the Sabatier reaction, the required $\mathrm{CO}_{2}$ and synthesizing $\mathrm{CH}_{4}$ are presented as:

$$
\begin{aligned}
& Q_{p}^{\mathrm{CO}_{2}}=Q_{s}^{\mathrm{H}_{2}, \text { out }, \mathrm{M}} \phi_{\mathrm{H}_{2}-\mathrm{CO}_{2}} \\
& Q_{p}^{\mathrm{CH}_{4}}=Q_{s}^{\mathrm{H}_{2}, \text { out }, \mathrm{M}} \phi_{\mathrm{H}_{2}-\mathrm{CH}_{4}}
\end{aligned}
$$

The recycled heat energy from the Sabatier reaction is related to the amount of $\mathrm{H}_{2}$ and can be similarly formulated as

$$
P_{p}^{\text {heat }}=Q_{s}^{\mathrm{CO}_{2}, \text { out }, \mathrm{M}} \phi_{\text {heat }}
$$

\subsubsection{Carbon capture system}

For the carbon capture system, the $\mathrm{CO}_{2}$ capture power consumption can be provided by the recycled heat from Sabatier reaction and CCPP simultaneously.

$$
P_{c}^{\mathrm{o}}=P_{c}^{\mathrm{ccs}}+P_{p}^{\text {heat }}
$$

\section{Proposed low-carbon economic dispatch model}

In this section, a low-carbon economic dispatch model of electricity and natural gas systems is formulated. In addition to the constraints of power system and natural gas system, the flexible operation mode of carbon capture system and PtG facility is also considered, and the presented model is further transformed into the MILP formulation to improve computing efficiency.

\subsection{Objective Function}

The objective of this paper is to minimize the overall cost of electricity and natural gas systems which consists of three parts: 


$$
\min F=F_{\mathrm{oc}}+F_{\mathrm{cp}}+F_{\mathrm{wp}}
$$

where $F, F_{\text {oc }}, F_{\text {cp }}$ and $F_{\text {wp }}$ are the functions of the total cost, the operational cost, the $\mathrm{CO}_{2}$ processing cost, and the penalty cost of wind power curtailment, respectively.

The first term in the right hand side of (32) focuses on the operational cost, which includes the generation and on/off cost of coal-fired units, production cost of natural gas wells, and the operational cost of natural gas storages. Among these costs, fuel consumption of gas-fired power generation units is usually described as the same quadratic function in (18).

$$
F_{\mathrm{oc}}=\sum_{t=1}^{N_{T}}\left\{\sum_{i=1}^{N_{F U}-N_{G U}} \rho_{i}\left[G\left(P_{i t}\right) I_{i t}+S U_{i t}+S D_{i t}\right]+\sum_{\omega=1}^{N_{G W}} \rho_{\omega} Q_{\omega t}+\sum_{s=1}^{N_{G S}} \rho_{s} Q_{s t}^{\mathrm{NG}, \mathrm{out}}\right\}
$$

The second term in (32) is related to the $\mathrm{CO}_{2}$ processing cost. As the definition aforementioned, the $\mathrm{CO}_{2}$ processing cost is the sum of the carbon tax cost of fossil fuel units, $\mathrm{CO}_{2}$ transmission and storage cost of CCPPs, and the $\mathrm{CO}_{2}$ capture cost from the atmosphere. Furthermore, the $\mathrm{CO}_{2}$ capture from atmosphere is treated as the $\mathrm{CO}_{2}$ emission reduction of electricity and natural gas systems, and this effect is reflected in the carbon tax cost.

$$
F_{\mathrm{cp}}=\sum_{t=1}^{N_{T}}\left[\rho^{\mathrm{ct}}\left(\sum_{i=1}^{N_{F U}} \mu_{i} P_{i t}-\sum_{c=1}^{N_{C C U}} Q_{c t}^{\mathrm{cc}}-\sum_{s=1}^{N_{C S}} Q_{s}^{\mathrm{CO}_{2}, \mathrm{in}, \mathrm{a}}\right)+\rho^{\mathrm{ts}}\left(\sum_{c=1}^{N_{C C U}} Q_{c t}^{\mathrm{cc}}-\sum_{s=1}^{N_{C S}} Q_{s}^{\mathrm{CO}_{2}, \mathrm{in}, \mathrm{cc}}\right)+\rho^{\mathrm{cc}} \sum_{s=1}^{N_{C S}} Q_{s}^{\mathrm{CO}_{2}, \mathrm{in}, \mathrm{a}}\right]
$$

The last term in (32) is referred to the penalty cost of wind power curtailment, which is proportional to the difference between available wind generation and actual wind generation.

$$
F_{\mathrm{wp}}=\sum_{t=1}^{N_{T}} \sum_{w=1}^{N_{W}} \rho_{w}\left(P_{w t}^{\mathrm{f}}-P_{w t}\right)
$$

\subsection{Constraints}

\subsubsection{Power system constraints}

The popular hourly constraints [31] of power systems mainly include the power supply and demand balance constraints (36), system spinning reserve constraints (37), power output limits of units and wind farms (38)-(39), unit ramping up and down constraints (40), start up and shut down cost constraints (41)-(42), and minimum on/off time constraints (43). Moreover, to reduce the complexity of proposed model, the power transmission limits (44) is expressed by DC power flow.

$$
\begin{aligned}
& \sum_{i=1}^{N_{F U}-N_{C C U}} P_{i t}+\sum_{c=1}^{N_{C C U}} P_{c t}^{\text {net }}+\sum_{w=1}^{N_{W}} P_{w t}+\sum_{p=1}^{N_{P}} P_{p t}^{\text {out }}=\sum_{d=1}^{N_{D}} P_{d t}+\sum_{p=1}^{N_{P}} P_{p t}^{\text {in }} \\
& \left\{\begin{array}{c}
\sum_{i=1}^{N_{F U}-N_{C C U}} P_{i, \max } I_{i t}+\sum_{c=1}^{N_{C C U}} P_{c, \max }^{\mathrm{net}} I_{c t}+\sum_{w=1}^{N_{W}} P_{w t} \geq \sum_{d=1}^{N_{D}} P_{d t}+S R_{t}^{\mathrm{up}} \\
\sum_{i=1}^{N_{F U}-N_{C C U}} P_{i, \min } I_{i t}+\sum_{c=1}^{N_{C C U}} P_{c, \min }^{\mathrm{net}} I_{c t}+\sum_{w=1}^{N_{W}} P_{w t} \leq \sum_{d=1}^{N_{D}} P_{d t}-S R_{t}^{\mathrm{down}}
\end{array}\right. \\
& I_{i t} P_{i, \text { min }} \leq P_{i t} \leq I_{i t} P_{i, \text { max }} \\
& 0 \leq P_{w t} \leq P_{w t}^{f} \\
& \left\{\begin{array}{l}
P_{i}-P_{i, t-1} \leq R_{i}^{U P} \cdot I_{i, t-1}+P_{i, \text { max }}\left(1-I_{i t}\right)+P_{i, \text { min }}\left(I_{i t}-I_{i, t-1}\right) \\
P_{i, t-1}-P_{i t} \leq R_{i}^{D N} \cdot I_{i t}+P_{i, \text { max }}\left(1-I_{i, t-1}\right)+P_{i, \text { min }}\left(I_{i, t-1}-I_{i t}\right)
\end{array}\right. \\
& \left\{\begin{array}{l}
S U_{i t} \geq s u_{i}\left(I_{i t}-I_{i, t-1}\right) \\
S U_{i t} \geq 0
\end{array}\right. \\
& \left\{\begin{array}{l}
S D_{i t} \geq s d_{i}\left(I_{i, t-1}-I_{i t}\right) \\
S D_{i t} \geq 0
\end{array}\right. \\
& \left\{\begin{array}{l}
\left(T_{i, t-1}^{\mathrm{on}}-T_{i, \text { min }}^{\mathrm{on}}\right)\left(I_{i, t-1}-I_{i, t}\right) \geq 0 \\
\left(T_{i, t-1}^{\mathrm{off}}-T_{i, \mathrm{~min}}^{\mathrm{off}}\right)\left(I_{i, t}-I_{i, t-1}\right) \geq 0
\end{array}\right.
\end{aligned}
$$




$$
\left|\sum_{k=1}^{N_{B}} G_{i j-k}\left(\sum_{a=1}^{N_{F U}-N_{C C U}} \Gamma_{k a} P_{a t}+\sum_{c=1}^{N_{C C U}} \Gamma_{k c} P_{c t}^{\text {net }}+\sum_{w=1}^{N_{W}} \Gamma_{k w} P_{w t}+\sum_{p=1}^{N_{p}} \Gamma_{k p}\left(P_{p t}^{\text {out }}-P_{p t}^{\text {in }}\right)-\sum_{d=1}^{N_{D}} \Gamma_{k d} P_{d t}\right)\right| \leq P_{i j, \max }
$$

\subsubsection{Natural gas system constraints}

Similar to the electric power system, the hourly steady gas flow constraints of natural gas system should be considered [32]. The natural gas pipelines can be classified based on whether compressors are included. For pipelines without any compressor, the gas flow model through transmission pipelines can be expressed as

$$
Q_{m n, t}\left|Q_{m n, t}\right|=C_{m n}^{2}\left(p_{m t}^{2}-p_{n t}^{2}\right)
$$

The gas transmission direction of pipeline $\mathrm{mm}$ is determined by the pressures of two ending node of this pipeline. If $p_{m t} \leq p_{n t}$, the gas flow $Q_{m n, t}$ will be larger than zero and the natural gas will be transmitted from node $m$ to node $n$. Otherwise, $Q_{m n, t}$ will be less than zero and the natural gas will be transmitted from node $n$ to node $m$. The pressure of each node should be limited by the lower and upper bounds.

$$
p_{m, \text { min }} \leq p_{m t} \leq p_{m, \text { max }}
$$

Note that some compressors are equipped in the pipelines to compensate the transmission pressure loss. For pipelines with compressors, the pressure at the outgoing node should be larger than the pressure at the incoming node. The compressor model of node pressure and gas flow can be simplified as [14] [33]:

$$
\begin{gathered}
p_{m t} \leq \lambda_{c} \cdot p_{n t} \\
Q_{m n, t}^{2} \leq C_{m n}^{2}\left(p_{m t}^{2}-p_{n t}^{2}\right)
\end{gathered}
$$

Furthermore, there are also other constraints consisting of the natural gas supply and demand balance constraint (49), gas output limits of gas wells (50), storage capacity, injection and withdrawal rate limits of gas storage facilities (51)-(55).

$$
\begin{gathered}
\sum_{\omega \in S(m)} Q_{\omega t}+\sum_{s \in S(m)} Q_{s t}^{\mathrm{NG}, \text { out }}+\sum_{p \in S(m)} Q_{p t}=\sum_{l \in S(m)} Q_{l t}+\sum_{i \in S(m)} Q_{i t}+\sum_{n g s \in S(m)} Q_{s t}^{\mathrm{NG}, \text { in }}+\sum_{n \in S(m)} Q_{m n, t} \\
Q_{\omega, \text { min }} \leq Q_{\omega t} \leq Q_{\omega, \text { max }} \\
E_{s t}^{\mathrm{NG}}=E_{s, t-1}^{\mathrm{NG}}+\left(Q_{s t}^{\mathrm{NG}, \text { in }}-Q_{s t}^{\mathrm{NG}, \text { out }}\right) \Delta t \\
E_{s, \text { min }}^{\mathrm{NG}} \leq E_{s t}^{\mathrm{NG}} \leq E_{s, \text { max }}^{\mathrm{NG}} \\
0 \leq Q_{s t}^{\mathrm{NG}, \text { out }} \leq Q_{s, \text { max }}^{\mathrm{NG}} \\
0 \leq Q_{s t}^{\mathrm{NG}, \text { in }} \leq Q_{s, \text { max }}^{\mathrm{NG,in}} \\
E_{s, 0}^{\mathrm{NG}}=E_{s, N_{T}}^{\mathrm{NG}}
\end{gathered}
$$

\subsubsection{Other constraints of electricity and natural gas systems}

In this paper, the electricity and natural gas systems are coupled by gas-fired units and PtG facilities. The natural gas consumption of gas-fired units can be modeled as (56) [22].

$$
Q_{i t}=\left[G\left(P_{i t}\right) I_{i t}+S U_{i t}+S D_{i t}\right] / \mathrm{HHV}_{\mathrm{NG}}
$$

where $\mathrm{HHV}_{\mathrm{NG}}$ is the higher heat value of natural gas.

The constraints of post-combustion carbon capture systems, PtG facilities and other components are shown in (1)-(31).

\subsection{Linearization of Equations}

The proposed model is formulated as a mixed-integer nonlinear programming (MINLP), which is difficult to be solved due to the presence of non-convex constraints (45) and (48). At present, mixed-integer linear programming (MILP) techniques can solve problems with up to hundred thousands of variables, and many related optimization software tools are available, such as CPLEX and GUROBI. Thus, in order to apply MILP techniques, nonlinear equations (18), (45) and (48) in the proposed dispatch model are approximated by piecewise linearization technique [15][34]. 


\section{Case studies}

A 6-bus power system/7-node natural gas system [22] and the modified IEEE 39-bus power system [33]/Belgian high calorific 20-node gas system [35] are adopted to demonstrate the effectiveness of the proposed low-carbon economic dispatch model. All case studies are implemented in MATLAB aided by Yalmip and CPLEX solvers.

\subsection{6-bus power system and 7-node natural gas system}

The 6-bus power system and 7-node natural gas system are shown in Fig. 4. The 6-bus power system consists of two gas-fired units G1 and G2, three coal-fired units G3-G5, one wind farm, one $\mathrm{PtG}$ facility, three electrical loads and seven transmission lines. Unit G5 with the highest $\mathrm{CO}_{2}$ emission intensity is retrofitted as a post-combustion CCPP unit. The PtG facility and unit G5 are both located at bus 3. The upward and downward system spinning reserve requirements are set as $10 \%$ of the total load at each period, and other parameters for units can be found in [24]. The carbon tax price, captured $\mathrm{CO}_{2}$ transmission and storage price, and $\mathrm{CO}_{2}$ capture price from atmosphere are set as 20\$/ton [28], $5 \$ /$ ton[4] and 200\$/ton [36], respectively. Forecast values of electrical load, gas load and wind generation are shown in Fig. 5 with peak values of 576.19MW, 200.27MW, 1835.5kcf, respectively.

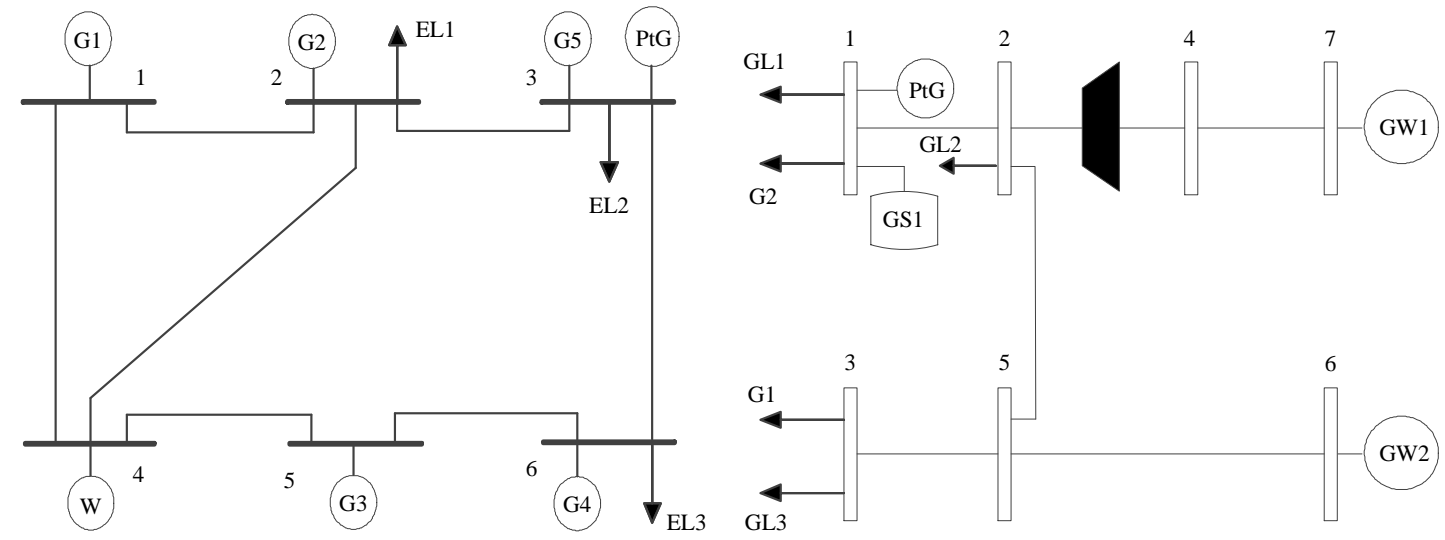

Fig. 4. 6-bus power system and 7-node natural gas system

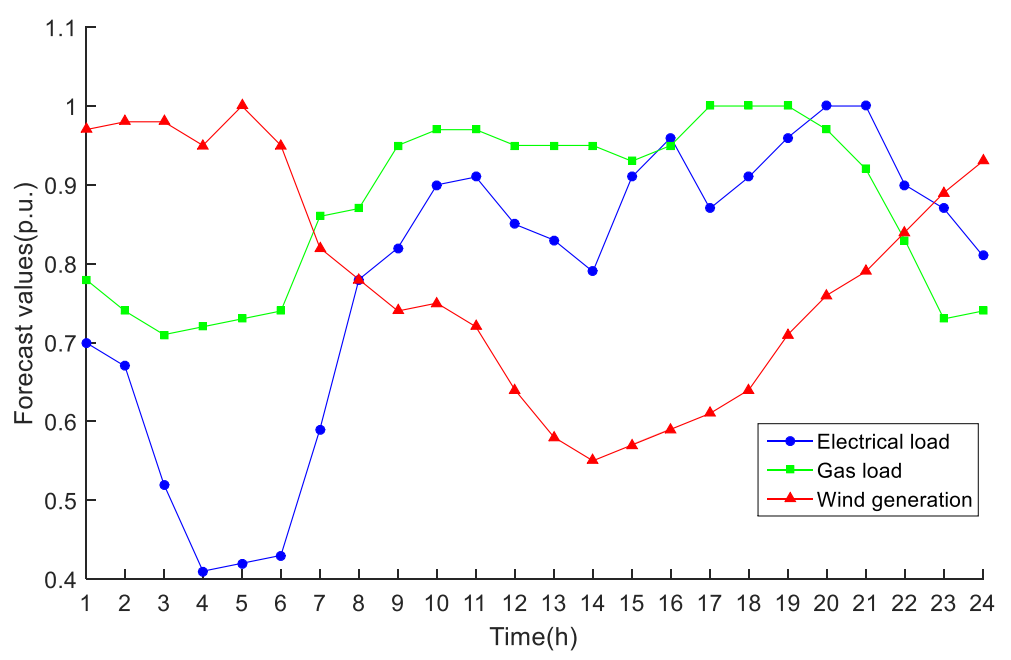

Fig. 5. Forecast values of electrical load, gas load and wind generation

Under high wind power penetration levels, five cases are analyzed to demonstrate the effectiveness of the proposed low-carbon economic dispatch model.

Case 1: Electricity and natural gas systems dispatch without carbon capture system and PtG facility

Case 2: Systems in Case 1 plus a PtG facility 
Case 3: Systems in Case 1 plus a carbon capture system

Case 4: Systems in Case 1 plus a carbon capture system and a PtG facility

Case 5: Electricity and natural gas systems dispatch considering the flexible operation mode of carbon capture system and PtG facility

Please note that in Case 3 and Case 4, all the captured $\mathrm{CO}_{2}$ of carbon capture systems will be transported and stored. Moreover, the heat energy from Sabatier reaction in Case 4 will be released into atmosphere directly, and $\mathrm{CO}_{2}$ will be captured from atmosphere in Case 2 and Case 4. Case 5 corresponds to the low-carbon economic dispatch model proposed in this paper.

\subsubsection{Hourly UC results}

The hourly UC solutions in Cases 1-5 are calculated and listed in Table 1 and Table 2. It can be seen that the hourly UC solutions in Cases 1-4 are the same. However, due to the flexible application of $\mathrm{H}_{2}$, the statuses of units 1, 2, 3 in Case 5 are different from Case 4 at certain hours.

Table 1 Hourly unit status in Cases 1-4

\begin{tabular}{|c|c|c|c|c|c|c|c|c|c|c|c|c|c|c|c|c|c|c|c|c|c|c|c|c|}
\hline Unit & \multicolumn{24}{|c|}{ Hours 1-24 } \\
\hline G1 & 1 & 1 & 1 & 1 & 1 & 1 & 1 & 1 & 1 & 1 & 1 & $\mathbf{0}$ & $\mathbf{0}$ & $\mathbf{0}$ & 1 & 1 & 1 & 1 & 1 & 1 & 1 & 1 & 0 & 0 \\
\hline $\mathrm{G} 2$ & 0 & 0 & 0 & 0 & 0 & 0 & 0 & 0 & 0 & 0 & 0 & 1 & 1 & 1 & 0 & 0 & 0 & 0 & 0 & 0 & 0 & 0 & 0 & 0 \\
\hline G3 & 1 & 1 & 0 & 0 & 0 & 0 & 0 & $\mathbf{0}$ & 0 & 1 & 1 & 1 & 1 & 1 & 1 & 1 & 1 & 1 & 1 & 1 & 1 & 1 & 1 & 1 \\
\hline G4 & 1 & 1 & 1 & 0 & 0 & 0 & 0 & 1 & 1 & 1 & 1 & 1 & 1 & 1 & 1 & 1 & 1 & 1 & 1 & 1 & 1 & 1 & 1 & 1 \\
\hline G5 & 1 & 1 & 1 & 1 & 1 & 1 & 1 & 1 & 1 & 1 & 1 & 1 & 1 & 1 & 1 & 1 & 1 & 1 & 1 & 1 & 1 & 1 & 1 & 1 \\
\hline
\end{tabular}

Table 2 Hourly unit status in Case 5

\begin{tabular}{|c|c|c|c|c|c|c|c|c|c|c|c|c|c|c|c|c|c|c|c|c|c|c|c|c|}
\hline Unit & \multicolumn{24}{|c|}{ Hours 1-24 } \\
\hline G1 & 1 & 1 & 1 & 1 & 1 & 1 & 0 & 0 & 0 & 0 & 1 & 1 & 1 & 1 & 1 & 1 & 1 & 1 & 1 & 1 & 1 & 1 & 0 & 0 \\
\hline $\mathrm{G} 2$ & 0 & 0 & 0 & 0 & 0 & 0 & 0 & 0 & 1 & 1 & 0 & $\mathbf{0}$ & $\mathbf{0}$ & $\mathbf{0}$ & 0 & 0 & 0 & 0 & 0 & 0 & 0 & 0 & 0 & 0 \\
\hline G3 & 1 & 1 & 0 & 0 & 0 & 0 & 1 & 1 & 1 & 1 & 1 & 1 & 1 & 1 & 1 & 1 & 1 & 1 & 1 & 1 & 1 & 1 & 1 & 1 \\
\hline G4 & 1 & 1 & 1 & 0 & 0 & 0 & 0 & 1 & 1 & 1 & 1 & 1 & 1 & 1 & 1 & 1 & 1 & 1 & 1 & 1 & 1 & 1 & 1 & 1 \\
\hline G5 & 1 & 1 & 1 & 1 & 1 & 1 & 1 & 1 & 1 & 1 & 1 & 1 & 1 & 1 & 1 & 1 & 1 & 1 & 1 & 1 & 1 & 1 & 1 & 1 \\
\hline
\end{tabular}

\subsubsection{Wind power curtailment results and analysis}

The wind power curtailment in Cases 1-5 is shown in Fig. 6. It can be seen in Case 1 that the wind power will be curtailed at hours 1-6. Compared to Case 1, the carbon capture system or PtG facility in Cases 2-3 can both reduce the amount of curtailed wind power. However, the power consumption of carbon capture system is limited by the treated $\mathrm{CO}_{2}$ amount, and the input power of PtG facility is limited by its maximum input power $100 \mathrm{MW}$, which still cannot absorb all the excessive wind power and thus makes curtailment happen partially. In Cases 4-5, both the carbon capture system and PtG facility are applied to improve the utilization rate of wind power, and the wind power curtailment does not happen.

In order to analyze the carbon capture system and PtG facility in details, the net power output of unit 5 and input power of PtG facility are presented in Fig. 7 and Fig. 8. Equipped with carbon capture system, unit 5 has lower net power output in Cases 3-5 than Cases 1-2 at hours 1-6, and nearly 20MW wind power can be supplied to electrical load directly rather than being curtailed. Due to the different unit commitment statuses in Cases 4-5, net power outputs of unit 5 in Case 5 are larger than Case 4 at hours 7-8. Moreover, net power outputs of unit 5 in Cases 4-5 are larger than Case 3 at hour 1, which is determined by the minimum input power $10 \mathrm{MW}$ of $\mathrm{PtG}$ facility. In addition, excessive wind power can 
be injected into the PtG facility in Cases 2, 4 and 5. Because the carbon capture system can increase the wind power penetration level, less wind power is injected into the PtG facility in Cases 4-5 than Case 2.

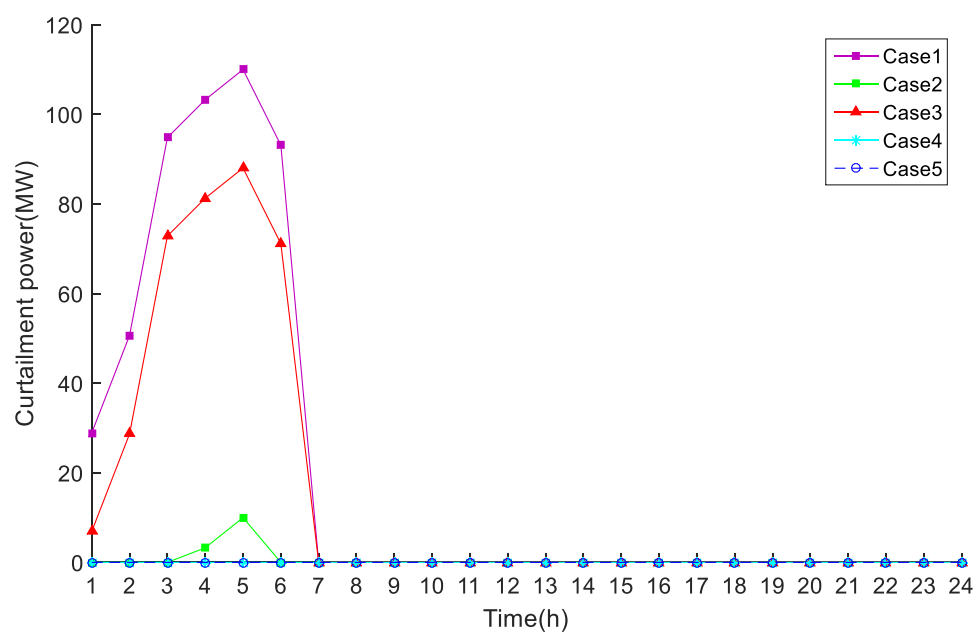

Fig. 6. Wind power curtailment

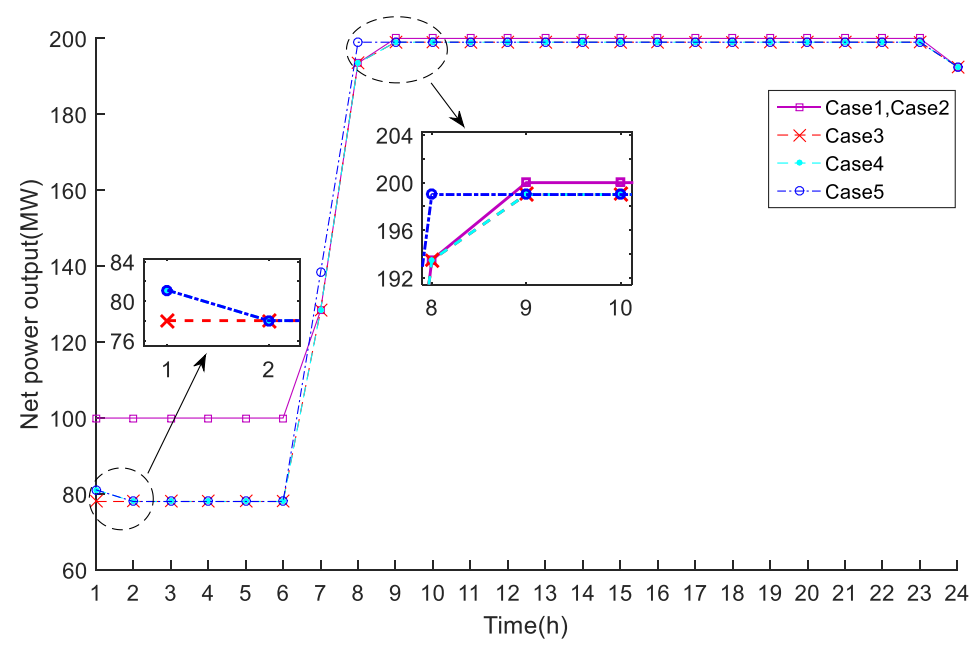

Fig. 7. Net power output of unit 5

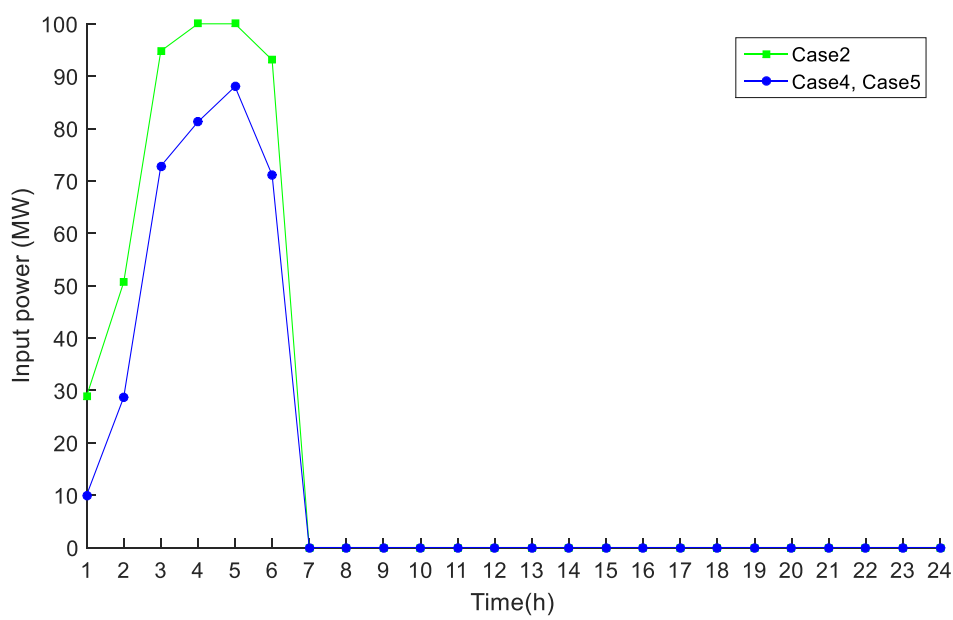

Fig. 8. Input power of PtG facility 
For the PtG facility in Cases 2, 4 and 5, excessive wind power is utilized to produce $\mathrm{H}_{2}$ at hours 1-6. Different from Cases 2 and 4, in which $\mathrm{CH}_{4}$ has to be synthesized after the production of $\mathrm{H}_{2}, \mathrm{H}_{2}$ and $\mathrm{CO}_{2}$ storage facilities in Case 5 can decouple the sequential process of producing $\mathrm{H}_{2}$ and synthesizing $\mathrm{CH}_{4}$. Hence, produced $\mathrm{H}_{2}$ in Case 5 can be applied to synthesize $\mathrm{CH}_{4}$ or generate power according to the need to minimize total cost of electricity and natural gas systems. The synthesized $\mathrm{CH}_{4}$, generating power of $\mathrm{H}_{2}$ gas turbine, and recycled heat power from Sabatier reaction are shown in Fig. 9 and Fig. 10. At hours 15-16 and 20-21, the electrical load is close to peak load. Part of the $\mathrm{H}_{2}$ is used to generate power by the $\mathrm{H}_{2}$ gas turbine, and the corresponding power outputs at hours 15, 16, 20 and 21 are 2.41MW. Furthermore, with the increasing consumption of natural gas loads, two natural gas wells operate with their maximum output at hours 10-21. The natural gas storage, which is expensive than the two natural gas wells, has to be used to meet the high natural gas load demand. Thus, to decrease the natural gas supply cost, part of the $\mathrm{H}_{2}$ from the $\mathrm{H}_{2}$ storage facility is converted into $\mathrm{CH}_{4}$ by Sabatier reaction at hours 12,17 and 20, and synthesized $\mathrm{CH}_{4}$ are $39.1 \mathrm{kcf}, 269.52 \mathrm{kcf}$ and $208.27 \mathrm{kcf}$, respectively. At the same time, the corresponding recycled heat powers from Sabatier reaction are 1.98MW, $13.62 \mathrm{MW}$ and $10.53 \mathrm{MW}$, respectively, which are used to capture $\mathrm{CO}_{2}$ for the carbon capture system.

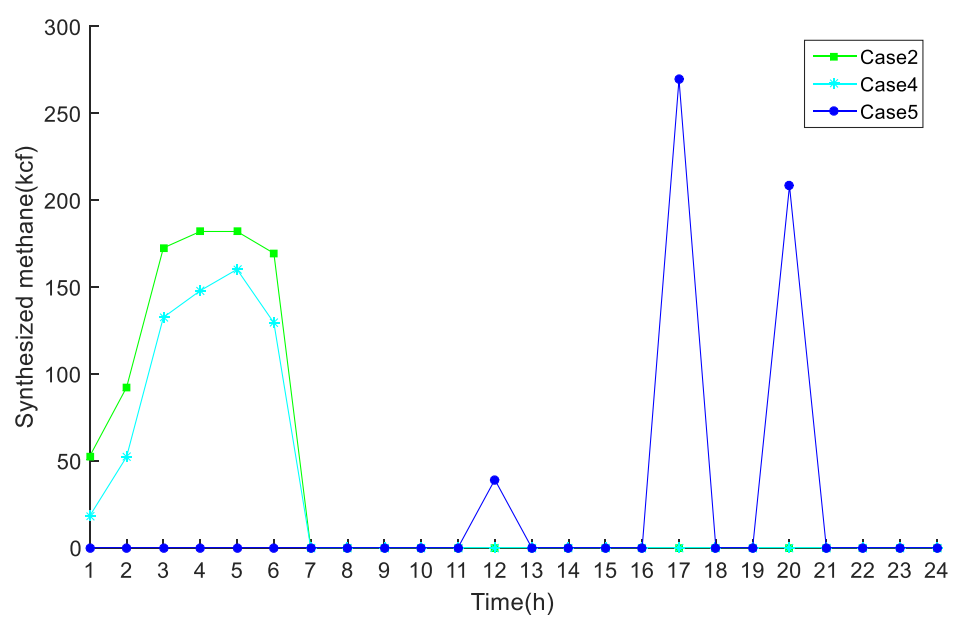

Fig. 9. Synthesized methane

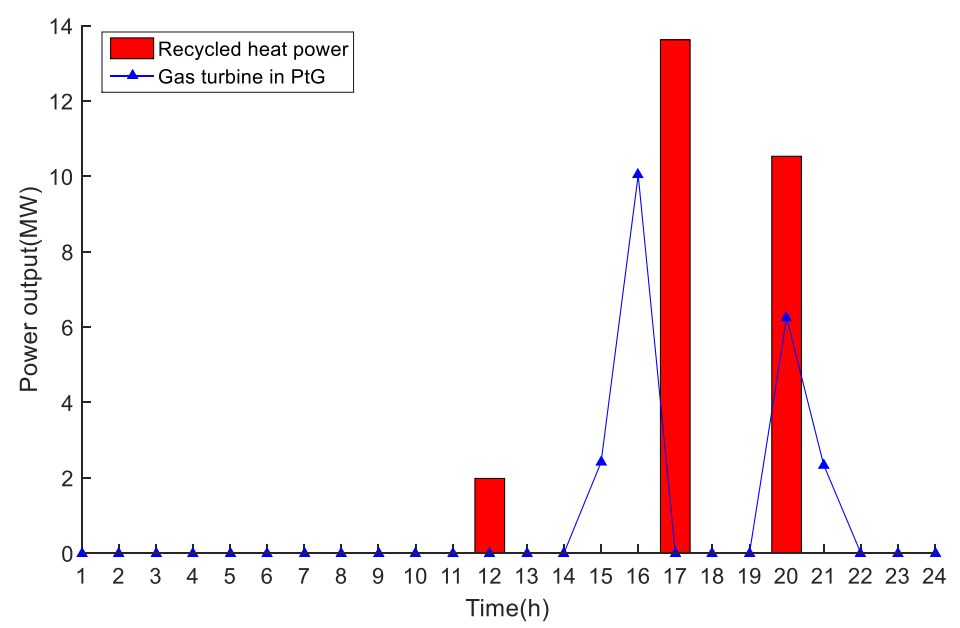

Fig. 10. Power output of $\mathrm{H}_{2}$ gas turbine and recycled heat power in Case 5

Furthermore, the surplus wind power of the whole dispatch cycle is $480.69 \mathrm{MW}$ in Case 1 , while it is utilized with different efficiencies in Cases 2-5. Since the efficiency of carbon capture system is set as a 
constant in this paper, the evaluation of efficiencies is mainly presented for the PtG facility in Case 2 and Case 5. The HHVs of $\mathrm{H}_{2}$ and $\mathrm{CH}_{4}$ are equal to $0.335 \mathrm{MBtu} / \mathrm{kcf}$ and $1.026 \mathrm{MBtu} / \mathrm{kcf}$, respectively, and the corresponding calculation results are shown in Table 3. It can be seen that the consumption of wind power is $467.45 \mathrm{MW}$ by the $\mathrm{PtG}$ facility in Case 2. However, part of the wind power is incorporated into the power system by the carbon capture system, and the wind power utilization is 351.89 MW by the PtG facility in Case 5. In addition, the efficiency of power to $\mathrm{H}_{2}$ is $71.45 \%$ in both cases. In Case 2, all the $\mathrm{H}_{2}$ is converted into $\mathrm{CH}_{4}$ with the efficiency of $76.57 \%$. In Case 5, part of the $\mathrm{H}_{2}$ is utilized by the gas turbine with an efficiency of $43.4 \%$, and the efficiency of power to $\mathrm{CH}_{4}$ is $89.44 \%$ due to the recycled heat energy from the Sabatier reaction. Furthermore, in order to obtain the roundtrip efficiencies, both the open cycle gas turbines (OCGTs) and combined cycle gas turbines (CCGTs) are adopted with the electrical efficiencies of $32 \%$ and $50 \%$, respectively [5]. Based on the OCGTs and CCGTs, the roundtrip efficiencies in Case 2 are $17.51 \%$ and $27.35 \%$, while the roundtrip efficiencies are $27.53 \%$ and $35.48 \%$, respectively, in Case 5. Moreover, if all the $\mathrm{H}_{2}$ is utilized by gas turbine in Case 5, the roundtrip efficiency will be approximately $31 \%$. Therefore, though the roundtrip efficiency in Case 5 are better than that in Case 2, both the utilization of surplus wind power in Case 2 and Case 5 have very low roundtrip efficiencies.

Table 3 Efficiencies of PtG facilities in Case 2 and Case 5

\begin{tabular}{ccccccc}
\hline Case & $\begin{array}{c}\text { Wind power } \\
\text { utilization (MW) }\end{array}$ & Power to $\mathrm{H}_{2}$ & $\mathrm{H}_{2}$ to power & $\mathrm{H}_{2}$ to $\mathrm{CH}_{4}$ & $\mathrm{CH}_{4}$ to power & $\begin{array}{c}\text { Roundtrip } \\
\text { efficiency }\end{array}$ \\
\hline 2 & 467.45 & $71.45 \%$ & - & $76.57 \%$ & $32 \% / 50 \%$ & $17.51 \% / 27.35 \%$ \\
5 & 351.89 & $71.45 \%$ & $43.4 \%$ & $89.44 \%$ & $32 \% / 50 \%$ & $27.53 \% / 35.48 \%$ \\
\hline
\end{tabular}

\subsubsection{Results and analysis of the proposed model}

Comparing to existing studies, the $\mathrm{CO}_{2}$ emission reduction, carbon capture system and PtG facility are considered simultaneously in this paper. In order to demonstrate the effectiveness of proposed model in Case1, a benchmarking system is introduced from the existing study [12], which merely focuses on the economic dispatch of electricity and natural gas systems. The comparison results are shown in Table 4. Different from the UC statuses in Case 1, cheaper coal-fired units G3-G5 are committed during the whole dispatch cycle of the bench-marking system, and thus $\$ 21414.35$ operation cost is saved. However, the penalty cost of wind power curtailment in the benchmarking system is larger than that in Case 1 due to the minimum on/off time constraints of G1-G5. Furthermore, since the $\mathrm{CO}_{2}$ emission intensity of coal-fired units G3-G5 is larger than the gas-fired units G1-G2, which results in more $\mathrm{CO}_{2}$ emission in the benchmarking system. Therefore, although the proposed model in Case 1 has a suboptimal operation cost, it can improve the wind power utilization and reduce $\mathrm{CO}_{2}$ emission at the same time.

Table 4 Comparisons of bench-marking system and Case 1

\begin{tabular}{cccc}
\hline System & Operation cost $(\$)$ & Penalty cost of wind & $\mathrm{CO}_{2}$ \\
power curtailment (\$) & 52348 & 5950.02 \\
\hline Bench-mariking & 516845.23 & 48069 & 5804.07 \\
Case 1 & 538259.58 & $\mathrm{t})$ & \\
\hline
\end{tabular}

To compare the influence of the carbon capture system and PtG facility on the low-carbon economic dispatch of electricity and natural gas systems, the corresponding costs of Cases 1-5 are shown in Table 5. Compared to Cases 1-4, Case 5 has the minimum total cost $\$ 641404.73$, which includes the minimum operation cost $\$ 532750.62$, minimum $\mathrm{CO}_{2}$ processing cost $\$ 108654.11$, and wind curtailment 
penalty $\$ 0$. It indicates that the proposed flexible operation mode of carbon capture system and PtG facility can reduce the overall cost and $\mathrm{CO}_{2}$ emission for the combined electricity and natural gas systems. In Case 3-4, the operation costs are both larger than that in Case 2, since part of the gas is consumed to provide the fixed energy consumption for the carbon capture system. Furthermore, synthesized $\mathrm{CH}_{4}$ can reduce the natural gas supply from gas wells, so both the fuel and operation costs in Case 2 and Case 4 are less than Case 3. As mentioned above, the carbon capture system and PtG facility can reduce the wind power curtailment, so the curtailment penalty \$1324 and \$24879.9 in Case 2-3 are less than $\$ 48069$ in Case 1.

Table 5 Costs in Cases 1-5

\begin{tabular}{ccccc}
\hline Case & Total cost $(\$)$ & Operation cost $(\$)$ & \multicolumn{2}{c}{$\begin{array}{c}\mathrm{CO}_{2} \\
\text { Penalty cost of wind power }\end{array}$} \\
\hline 1 & 702407.63 & 538259.58 & 116079.05 & 48069 \\
2 & 659500.78 & 533581.09 & 124595.69 & 1324 \\
3 & 684094.84 & 539162.07 & 110052.87 & 34879.90 \\
4 & 652259.43 & 535640.16 & 116619.26 & 0 \\
5 & 641404.73 & 532750.62 & 108654.11 \\
\hline
\end{tabular}

Furthermore, to discuss the $\mathrm{CO}_{2}$ processing cost in Cases 1-5, the carbon tax cost, cost of capturing $\mathrm{CO}_{2}$ from atmosphere, and the transmission \& storage cost are shown in Table 6. Due to the presence of carbon capture system in unit 5, the carbon tax costs in Cases 3-5 are less than Cases 1-2. However, \$2106, \$2054.28 and \$2347.56 have to be spent in Cases 3, 4 and 5, respectively, for transmitting and storing all or part of the captured $\mathrm{CO}_{2}$. In Case 5, although part of the captured $\mathrm{CO}_{2}$ from the carbon capture system is used to participate in the Sabatier reaction, the recycled heat power is supplied to the carbon capture system for capturing $\mathrm{CO}_{2}$. Therefore, the final transmission and storage cost of $\mathrm{CO}_{2}$ in Case 5 is larger than Cases 3-4. To provide $\mathrm{CO}_{2}$ for the Sabatier reaction in PtG facility, \$9462.93 and $\$ 7123$ in Cases 2 and 4 have to be spent to capture $\mathrm{CO}_{2}$ from the atmosphere for synthesizing $\mathrm{CH}_{4}$, respectively. Nevertheless, this part of $\mathrm{CO}_{2}$ can be provided exclusively by the carbon capture system in Case 5, which is considered as cost free comparing to other additional $\mathrm{CO}_{2}$ sources. In addition, since we consider the captured $\mathrm{CO}_{2}$ from atmosphere as the $\mathrm{CO}_{2}$ emission reduction, the carbon tax costs in Cases 2 and 4 are less than that of Cases 1 and 3, despite that the same amount of $\mathrm{CO}_{2}$ emission is emitted by units 1-5 in Cases 1-2 and in Cases 3-4.

Table $6 \mathrm{CO}_{2}$ processing costs in Cases 1-5

\begin{tabular}{ccccc}
\hline Case & $\mathrm{CO}_{2}$ & Carbon tax cost $(\$)$ & Capture $\mathrm{CO}_{2}$ cost from & \multicolumn{2}{c}{ Transmission \& storage } \\
& processing cost $(\$)$ & atmosphere $(\$)$ & 0 & 0 \\
\hline 1 & 116079.05 & 116079.05 & 9462.93 & 0 \\
2 & 124595.69 & 115132.76 & 0 & 2106.00 \\
3 & 110052.87 & 107946.87 & 7123.58 & 2054.28 \\
4 & 116619.26 & 107441.40 & 0 & 2347.56 \\
\hline 5
\end{tabular}

\subsubsection{Sensitivity of carbon tax price and wind power penetration level}

Carbon tax price and wind power penetration level are two important influencing factors in Cases 1-5, and the changes of these two factors will determine whether the presented models have a promising application in the real world. Therefore, the reference values of wind power penetration are chosen as those from Fig. 5, and the sensitivity analysis of proposed models with different carbon tax 
prices and wind power penetration levels is shown in Fig. 11.

The increase of carbon tax price will result in higher total costs in Cases 1-5. Due to the installation of PtG facility in Case 2, part of the excessive wind power can be utilized and the total cost can be saved compared to Case 1. As the analysis before, the PtG facility can absorb more excessive wind power than the carbon capture system in the test system. When the carbon price is less than $\$ 40 /$ ton, the total cost in Case 2 is less than Case 3. However, if the carbon tax price is higher than $\$ 40 /$ ton, the carbon capture system will save more $\mathrm{CO}_{2}$ processing cost in Cases 3-5 than in Cases 1-2, and less total cost in Case 3 will be spent than in Case 2. Especially in Case 5, the excessive wind power can be utilized more flexible, and the advantage of the operation solution of Case 5 turns to be more obvious with the increase of carbon tax price.

In addition, the total costs in Cases 1-5 will be reduced when the wind power penetration level increases. As mentioned above, the total costs in Cases 4-5 are lower than in Cases 2-3, where Cases 2 and 3 only consider the carbon capture systems or PtG facilities. Compared to Case 4, the excessive wind power can be further utilized with different $\mathrm{H}_{2}$ applications in Case 5, and it will save more total cost than Case 4 when sufficient amount of excessive wind power is available.


Fig. 11. Sensitivity of carbon tax prices and different wind power penetration

\subsubsection{Cost-benefit analysis of Cases 4-5}

In order to better describe the linkage to real applications of the presented models, both the investment and operation costs of the carbon capture system and PtG facility should be considered in the real world scenarios. Thus, the cash flow analysis is further used to evaluate the feasibility of proposed models for Cases 4-5. The discount rate is assumed to be 5\%, and the operation life span is 20 years. The investment cost of post-combustion carbon capture systems is set as $908 \$ / \mathrm{kW}$ in Cases 4-5 [24], and the investment cost of PtG facility is set as $1085 \$ / \mathrm{kW}$ in Case 4. In Case 5, the investment costs for $\mathrm{H}_{2}$ storage facility, $\mathrm{H}_{2}$ gas turbine and $\mathrm{CO}_{2}$ storage facility are set as $9406.5 \$ / \mathrm{kcf}$, $320000 \$ / M W$ and $6937.665 \$ / \mathrm{kcf}[32]$, respectively.

The total cost over the operation life span and investment cost in Case 4 will be $\$ 81473457.1$ less than Case 1, which is treated as the cost savings in this paper. To calculate the additional investment cost in Case 5, the capacity of $\mathrm{H}_{2}$ storage facility, $\mathrm{H}_{2}$ gas turbine and $\mathrm{CO}_{2}$ storage facility should be determined. In this paper, the capacity of $\mathrm{H}_{2}$ gas turbine is set as $30 \%$ of the maximum PtG input power, and the maximum input flow of $\mathrm{H}_{2}$ storage facility is $728 \mathrm{kcf} / \mathrm{h}$ calculated by the maximum PtG input power 100MW. To determine the optimal capacity of $\mathrm{H}_{2}$ storage facility, we set the reference value of $\mathrm{H}_{2}$ storage capacity as $728 \mathrm{kcf}$. The injection/withdrawal rate per hour is set as 0.25 times of $\mathrm{H}_{2}$ storage capacity. The reference value and injection/withdrawal rate per hour of $\mathrm{CO}_{2}$ storage facility are set as 
0.25 times of $\mathrm{H}_{2}$ storage facility. The total cost and cost savings of different $\mathrm{H}_{2}$ storage capacities are shown in Fig.12.
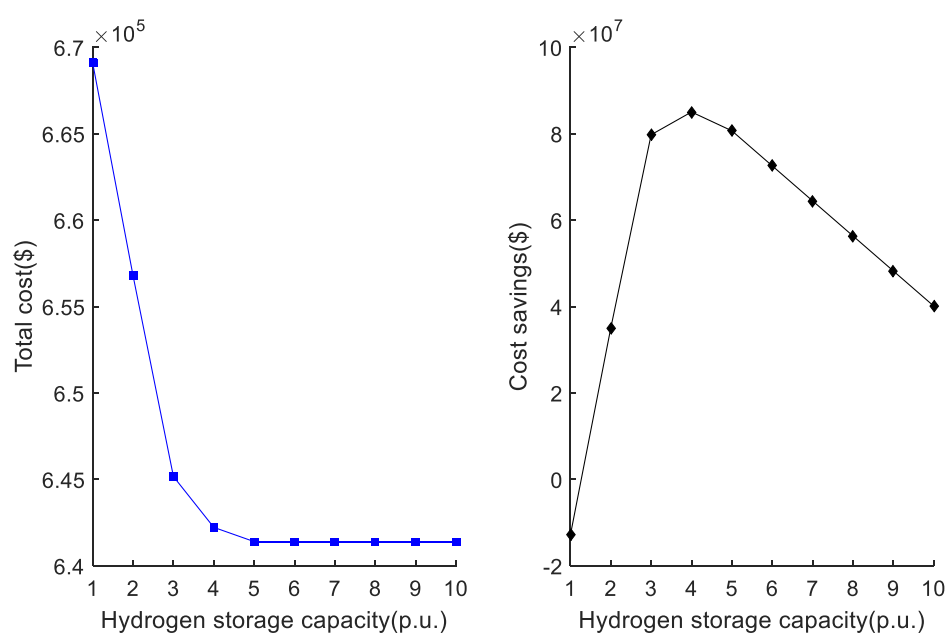

Fig.12 Total cost and cost savings of different $\mathrm{H}_{2}$ storage capacities in Case 5

When the $\mathrm{H}_{2}$ storage capacity is larger than $3640 \mathrm{kcf}$, the total cost will achieve the minimum value. However, if the $\mathrm{H}_{2}$ storage capacity is $2912 \mathrm{kcf}$, the cost savings will achieve the maximum value. Therefore, the $\mathrm{H}_{2}$ storage capacity $2912 \mathrm{kcf}$ is better than 3640kcf in terms of life cycle cost, and the cost savings over the operation life span is $\$ 85055729.62$. According to the discussion for Fig.11, the cost savings will be larger with the increase of wind power penetration level and carbon tax price.

\subsection{Modified IEEE 39-bus power system and 20-bus natural gas system}

To further discuss the characteristics of proposed models in Cases 1-5 for larger systems, the modified IEEE 39-bus power system and Belgian 20-node gas system are integrated in Fig. 13. G1, G7 and G8 are gas-fired units, which are connected to nodes 5, 14 and 2 of the natural gas system, and other thermal units are coal-fired units. In addition, two carbon capture systems are installed at G9 and G10, respectively. PtG1 and PtG2 are connected to bus 38 and bus 39 in the power system, which will inject $\mathrm{CH}_{4}$ to natural gas system at node 8 and node 14, respectively. The related costs in Cases 1-5 are shown in Table 7. It can be seen that excessive wind power can be utilized entirely in Cases 4-5, and the least total cost can be achieved in Case 5 .

Table 7 Related costs in Cases 1-5

\begin{tabular}{|c|c|c|c|c|}
\hline Case & Total cost $(\$)$ & Fuel cost $(\$)$ & $\begin{array}{c}\mathrm{CO}_{2} \\
\text { Processing cost }(\$)\end{array}$ & $\begin{array}{c}\text { Penalty cost of wind power } \\
\text { curtailment (\$) }\end{array}$ \\
\hline 1 & 21121076.01 & 19814310.14 & 1007730.88 & 299035 \\
\hline 2 & 20869762.06 & 19788002.03 & 1059124.03 & 22636 \\
\hline 3 & 20953446.86 & 19846083.93 & 945521.23 & 161841.71 \\
\hline 4 & 20805604.24 & 19831670.42 & 973933.82 & 0 \\
\hline 5 & 20752805.94 & 19809773.24 & 943032.71 & 0 \\
\hline
\end{tabular}




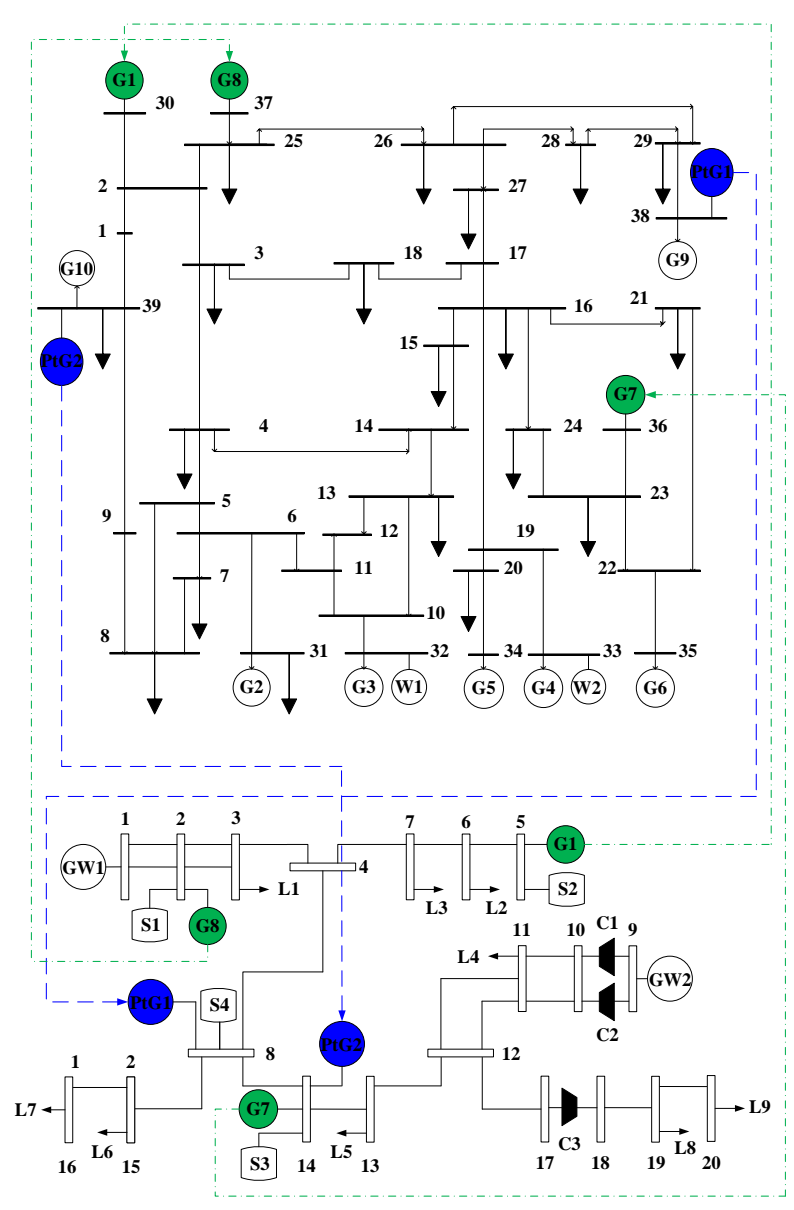

Fig. 13. Modified 39-bus power system and 20-bus natural gas system

For the sensitivity of carbon tax price and wind power penetration, the major conclusions are similar to the coupled 6-bus electrical power and 7-node natural gas system in Cases 1-5. To discuss the cost-benefit of Cases 4-5, the parameter setting principles are the same as the coupled 6-bus electrical power and 7-node natural gas system. In Case 5, the capacities of the two $\mathrm{H}_{2}$ gas turbines are both $100 \mathrm{MW}$, and the reference capacity values of the two $\mathrm{H}_{2}$ storage facilities are $1456 \mathrm{kcf}$ and $2784 \mathrm{kcf}$, respectively. Unlike the total cost, which will achieve the minimum value if the two $\mathrm{H}_{2}$ storage facilities are larger than 6 times of reference capacity values, the investment profit achieves the maximum value at 4 times of the reference capacity values. Hence, we choose $5824 \mathrm{kcf}$ and $11136 \mathrm{kcf}$ as the capacities of the two $\mathrm{H}_{2}$ storage facilities, respectively. The cost savings under different carbon tax prices and wind power penetration in Cases 4-5 are calculated and shown in Fig. 14. 

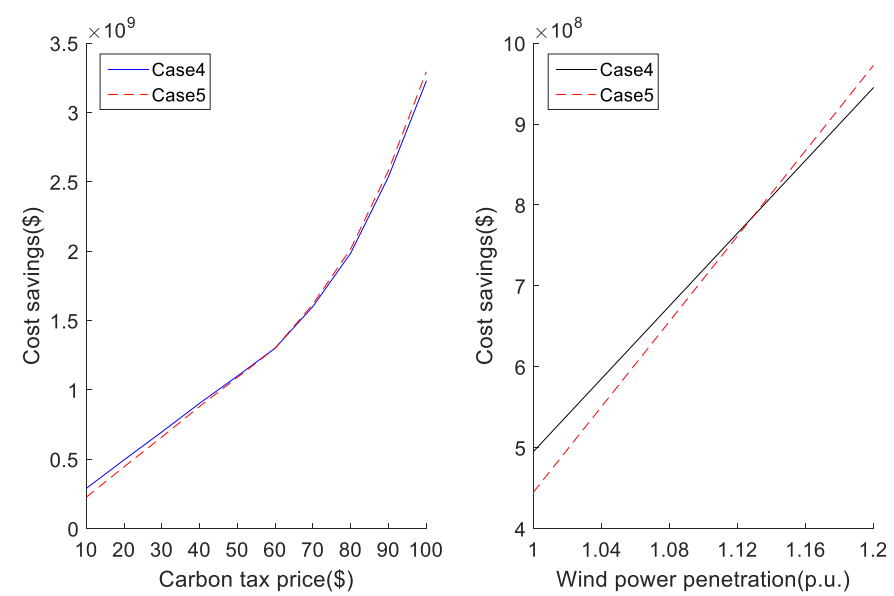

Fig. 14. Cost savings under different carbon tax prices and wind power penetration levels in Cases 4-5

When the carbon tax price is less than $\$ 60 /$ ton and the wind power penetration level is less than 1.14 times of the reference value, more cost savings in Case 4 is achieved than Case 5. However, if the carbon tax price and wind power penetration are larger than these values mentioned above, the cost savings in Case 5 will be higher than Case 4 .

\section{Conclusion}

This paper has proposed a low-carbon economic dispatch model under the constraints of electricity and natural gas systems. To reduce $\mathrm{CO}_{2}$ emission and increase wind power utilization as much as possible, both the post-combustion carbon capture systems and power-to-gas facilities have been considered, and a flexible operation mode is further studied to reduce the overall cost. In addition to the conventional operation cost and penalty cost of wind power curtailment, the $\mathrm{CO}_{2}$ processing cost is also included in the presented model. Simulation results demonstrate that the post-combustion carbon capture system and power-to-gas facility can reduce the wind power curtailment by approximately $27.43 \%$ and $97.25 \%$, respectively, while all the surplus power of wind power can be utilized and nearly $8.68 \%$ overall cost can be reduced in the proposed flexible operation mode. Furthermore, the overall costs of the presented models are sensitive to the carbon tax price and wind power penetration level, and the profit advantage of flexible operation mode will be more obvious with the increase of carbon tax price and wind power penetration level. However, due to the investment cost of additional facilities, the total cost and investment profit cannot reach minimum at the same time.

\section{Acknowledgement}

This work is financially supported by the National Natural Science Foundation of Hebei Province (No. F2016203507); and the National Natural Science Foundation of China (No. 61374098).

\section{References}

[1] Paris Agreement, 2015 [Online]. Available: http://www.htemp.com/detail/16876.html.

[2] Saboori H, Hemmati R. Considering Carbon Capture and Storage in Electricity Generation Expansion Planning. IEEE Trans Sust Energy 2016; 7(4): 1371-1378.

[3] EIA, Annual Energy Review, 2011 [Online]. Available: http://www.eia.doe.gov/emeu/aer/.

[4] Rubin ES., Davison JE., Herzog HJ. The cost of $\mathrm{CO}_{2}$ capture and storage. Int J Green H Gas Con 2015; 40: 378-400.

[5] Clegg S, Mancarella P. Integrated Modeling and Assessment of the Operational Impact of Power-to-Gas (P2G) on Electrical 
and Gas Transmission Networks. IEEE Trans Sust Energy 2015; 6(4): 1234-1243.

[6] Qadrdan M, Abeysekera M, Chaudry M, et al. Role of power-to-gas in an integrated gas and electricity system in Great Britain. Int J Hydrogen Energy 2015; 40: 5763-5775.

[7] Zeng Q, Fang J, Li J, et al. Steady-state analysis of the integrated natural gas and electric power system with bi-directional energy conversion. Appl Energy 2016; 184: 1483-1492.

[8] Li T, Eremia M, Shahidehpour M. Interdependency of Natural Gas Network and Power System Security. IEEE Trans Power Syst 2008; 23(4): 1817-1824.

[9] Liu C, Shahidehpour M, Fu Y, et al. Security-Constrained Unit Commitment with Natural Gas Transmission Constraints. IEEE Trans Power Syst 2009; 24(3): 1523-1536.

[10] Alabdulwahab A, Abusorrah A, Zhang X, et al. Stochastic Security-Constrained Scheduling of Coordinated Electricity and Natural Gas Infrastructures. IEEE Syst J 2015; 3(14): 1-10.

[11] Zhang X, Shahidehpour M, Alabdulwahab A, et al. Hourly Electricity Demand Response in the Stochastic Day-Ahead Scheduling of Coordinated Electricity and Natural Gas Networks[J]. IEEE Trans Power Syst 2016; 31(1): 592-601.

[12] Alabdulwahab A, Abusorrah A, Zhang X, et al. Coordination of Interdependent Natural Gas and Electricity Infrastructures for Firming the Variability of Wind Energy in Stochastic Day-Ahead Scheduling. IEEE Trans on Sust Energy 2015; 6(2): 606-615.

[13] Zhao B, Conejo AJ, Sioshansi R. Unit Commitment under Gas-Supply Uncertainty and Gas-Price Variability. IEEE Trans Power Syst 2017; 32(3): 2394-2405.

[14] Correa-Posada CM, Sánchez-Martın P. Security-Constrained Optimal Power and Natural-Gas Flow. IEEE Trans Power Syst 2014; 29(4): 1780-1787.

[15] Correa-Posada CM, Sánchez-Martın P. Integrated power and natural gas model for energy adequacy in short-term operation. IEEE Trans Power Syst 2015; 30(6): 3347-3355.

[16] Bai L, Li F, Jiang T, et al. Robust scheduling for wind integrated energy systems considering gas pipeline and power transmission N-1 contingencies. IEEE Trans Power Syst 2017; 32(2): 1582-1584.

[17] Qiao Z, Guo Q, Sun H, et al. An interval gas flow analysis in natural gas and electricity coupled networks considering the uncertainty of wind power. Appl Energy 2017; 201: 343-353

[18] Bai L, Li F, Cui H, et al. Interval optimization based operating strategy for gas-electricity integrated energy systems considering demand response and wind uncertainty. Appl Energy 2016; 167: 270-279.

[19] Li G, Zhang R, Jiang T, et al. Optimal dispatch strategy for integrated energy systems with CCHP and wind power. Appl Energy 2017; 192: 408-419.

[20] Zheng J, Wu Q, Jing Z. Coordinated scheduling strategy to optimize conflicting benefits for daily operation of integrated electricity and gas networks. Appl Energy 2017; 192: 370-381.

[21] Li G, Zhang R, Jiang T, et al. Security-constrained bi-level economic dispatch model for integrated natural gas and electricity systems considering wind power and power-to-gas process. Appl Energy 2017; 194: 696-704.

[22] C. He, L. Wu, T. Liu, et al. Robust Co-optimization Scheduling of Electricity and Natural Gas Systems via ADMM. IEEE Trans Sust Energy 2016; 1-11.

[23] Alkano D, Scherpen J. Distributed supply coordination for Power-to-Gas facilities embedded in energy grids. IEEE Trans Smart Grid 2016; 1-12.

[24] Ban M, Yu J, Shahidehpour M, et al. Integration of power-to-hydrogen in day-ahead security constrained unit commitment with high wind penetration. J Mod Power Syst Clean Energy 2017; 5(3): 337-349.

[25] Chen Q, Kang C, Xia Q. Modeling flexible operation mechanism of capture power plant and its effects on power-system operation. IEEE Trans Energy Convers 2010; 25(3): 853-861.

[26] Reiter G, Lindorfer J. Evaluating $\mathrm{CO}_{2}$ sources for power-to-gas applications - A case study for Austria. J CO $2 ~ U t i l ~ 2015 ; 10$ : $40-49$. 
[27] Reiter G, Lindorfer J. Global warming potential of hydrogen and methane production from renewable electricity via power-to-gas technology. Int J Life Cycle Assess 2015; 20:477-489.

[28] Ji Z, Kang C, Chen Q, et al. Low-Carbon Power System Dispatch Incoporating Carbon Capture Power Plants. IEEE Trans Power Syst 2013; 28(4): 4615-4623.

[29] Parra D, Zhang X, Bauer C, et al. An integrated techno-economic and life cycle environmental assessment of power-to-gas systems. Appl Energy 2017; 193: 440- 454.

[30] Guandalini G, Campanari S, Romano MC. Power-to-gas plants and gas turbines for improved wind energy dispatchability: Energy and economic assessment. Appl Energy 2015; 147: 117-130.

[31] Fu Y, Shahidehpour M, Li ZY. Security-constrained unit commitment with AC constraints. IEEE Trans Power Syst 2005; 20(2):1001-1013.

[32] Unsihuay C, Marangon Lima JW, et al. Modeling the Integrated Natural Gas and Electricity Optimal Power Flow. IEEE Power Engineering Society General Meeting 2007; 1-7.

[33] Munoz J, Jimenez-Redondo N, Perez-Ruiz J, et al. Natural gas network modeling for power systems reliability studies. IEEE/Power Eng Soc General Meeting 2003; 4: 23-26.

[34] Carrio'n M, Arroyo JM. A computationally efficient mixed-integer linear formulation for the thermal unit commitment problem. IEEE Trans Power Syst 2006; 21(3):1371-1378

[35] Zimmerman RD, Murillo-Sanchez CE, Thomas RJ. Matpower: Steady-state operations, planning, analysis tools for power systems research and education. IEEE Trans Power Syst 2011; 26(1): 12-19.

[36] Ebaid MSY., Hammad M, Alghamdi T. THERMO economic analysis OF PV and hydrogen gas turbine hybrid power plant of 100 MW power output. Int J Hydrogen Energy 2015; 40: 12120-12143. 